\title{
Mitogenomic phylogeny and fossil-calibrated mutation rates for all F- and M-type mtDNA genes of the largest freshwater mussel family, the Unionidae (Bivalvia)
}

\author{
ALEXANDRA ZIERITZ1,*,ø, ELSA FROUFE ${ }^{2}$, IVAN BOLOTOV ${ }^{3,4,5}$, DUARTE V. GONÇALVES ${ }^{2, \bullet,}$ \\ DAVID C. ALDRIDGE ${ }^{6}$, ARTHUR E. BOGAN 7 , HAN MING GAN ${ }^{8}$, \\ ANDRÉ GOMES-DOS-SANTOS ${ }^{2,9}$, RONALDO SOUSA ${ }^{10}$, AMILCAR TEIXEIRA $^{11}$, \\ SIMONE VARANDAS ${ }^{12}$, DAVID ZANATTA ${ }^{13}$ and MANUEL LOPES-LIMA ${ }^{2,14}$ \\ ${ }^{1}$ School of Geography, Sir Clive Granger Building, University of Nottingham, University Park, NG7 2RD \\ Nottingham, UK \\ ${ }^{2}$ CIIMAR/CIMAR - Interdisciplinary Centre of Marine and Environmental Research, University \\ of Porto, Terminal de Cruzeiros do Porto de Leixões, Av. General Norton de Matos s / n, 4450-208 \\ Matosinhos, Portugal \\ ${ }^{3}$ Federal Center for Integrated Arctic Research, Russian Academy of Sciences, Severnaya Dvina Emb. 23, \\ 163000 Arkhangelsk, Russian Federation \\ ${ }^{4}$ Northern Arctic Federal University, Northern Dvina Emb. 17, 163002 Arkhangelsk, Russian Federation \\ ${ }^{5}$ Saint-Petersburg State University, Universitetskaya Emb. 7/9, 199034 Saint Petersburg, Russian \\ Federation \\ ${ }^{6}$ Aquatic Ecology Group, The David Attenborough Building, Department of Zoology, University of \\ Cambridge, Pembroke Street, Cambridge CB2 3QZ, UK \\ ${ }^{7}$ Research Laboratory, North Carolina State Museum of Natural Sciences, 11 West Jones St., Raleigh, NC \\ 27601, USA \\ ${ }^{8}$ Centre for Integrative Ecology, School of Life and Environmental Sciences, Deakin University, Geelong, \\ 3220, VIC, Australia \\ ${ }^{9}$ Department of Biology, Faculty of Sciences, University of Porto, Rua do Campo Alegre s / n, 4169-007, \\ Porto, Portugal \\ ${ }^{10}$ CBMA - Centre of Molecular and Environmental Biology, Department of Biology, University of Minho, \\ Campos de Gualtar, 4710-057 Braga, Portugal \\ ${ }^{11}$ Centro de Investigação de Montanha (CIMO), Instituto Politécnico de Bragança, Campus de Santa \\ Apolónia, 5300-253 Bragança, Portugal \\ ${ }^{12}$ CITAB-UTAD - Centre for Research and Technology of Agro-Environment and Biological Sciences, \\ University of Trás-os-Montes and Alto Douro, Apartado 1013, 5001-811 Vila Real, Portugal \\ ${ }^{13}$ Biology Department, Institute for Great Lakes Research, Central Michigan University, Biosciences \\ 2408, Mount Pleasant, MI 48859, USA \\ ${ }^{14} \mathrm{CIBIO} /$ InBIO - Research Center in Biodiversity and Genetic Resources, Universidade do Porto, \\ Campus Agrário de Vairão, Rua Padre Armando Quintas, 4485-661 Vairão, Portugal
}

Received 21 August 2020; revised 15 October 2020; accepted for publication 20 October 2020

The Unionidae represent an excellent model taxon for unravelling the drivers of freshwater diversity, but, phylogeographic studies on Southeast Asian taxa are hampered by lack of a comprehensive phylogeny and mutation rates for this fauna. We present complete female- $(\mathrm{F})$ and male-type (M) mitogenomes of four genera of the Southeast

*Corresponding author. E-mail:Alexandra.zieritz@nottingham. ac.uk 
Asian clade Contradentini+Rectidentini. We calculate substitution rates for the mitogenome, the 13 protein-coding genes, the two ribosomal units and three commonly used fragments (co1, nd1 and 16S) of both F- and M-mtDNA, based on a fossil-calibrated, mitogenomic phylogeny of the Unionidae. Phylogenetic analyses, including an $\mathrm{M}+\mathrm{F}$ concatenated dataset, consistently recovers a monophyletic Gonideinae. Subfamily-level topology is congruent with that of a previous nuclear genomic study and with patterns in mitochondrial gene order, suggesting Unionidae F-type 2 as a synapomorphy of the Gonideinae. Our phylogeny indicates that the clades Contradentini+Rectidentini and Lamprotulini+Pseudodontini+Gonideini split in the early Cretaceous ( 125 Mya), and that the crown group of Contradentini+Rectidentini originated in the late Cretaceous ( 79 Mya). Most gonideine tribes originated during the early Palaeogene. Substitution rates were comparable to those previously published for F-type co1 and 16S for certain Unionidae and Margaritiferidae species (pairs).

ADDITIONAL KEYWORDS: evolutionary biogeography - mitochondrial DNA - palaeogeography - selection substitution rate - tropical biodiversity.

\section{INTRODUCTION}

Southeast Asia is a region of exceptional and highly threathened biodiversity, being comprised of four of the 35 global biodiversity hotspots (Mittermeier et al., 2011). Understanding patterns and drivers of this diversity is crucial for prioritizing conservation efforts, particularly in freshwater habitats, where species are being lost faster than in any other realm (Dudgeon et al., 2006; Reid et al., 2019). Freshwater mussels of the order Unionida represent an excellent model taxon for understanding causes of and threats to tropical freshwater diversity, owing to their restriction to freshwater habitats throughout their lifecycle, exceptional diversity in the region and high sensitivity to habitat degradation and other anthropogenic factors (Wächtler et al., 2001; Gallardo et al., 2018; Lopes-Lima et al., 2018; Zieritz et al., 2018a, b). Unfortunately, biogeographical studies on Southeast Asian Unionida are currently hampered by a lack of a comprehensive phylogeny of this fauna. Southeast Asian Unionida have received little scientific attention until recent intensification of sampling and sequencing efforts (Pfeiffer \& Graf, 2015; Zieritz et al., 2016, 2018a, 2020; Bolotov et al., 2017a, b; Konopleva et al., 2019).

The vast majority (99\%) of the approximately 135 Unionida species from Southeast Asia fall into the family Unionidae, comprising 714 currently recognized species globally (Zieritz et al., 2018a; Graf \& Cummings, 2019). The evolutionary relationships among suprageneric clades of the Unionidae has been the subject of a number of recent studies, but, the number of these clades and the relationships between them remain contentious. Based on a twolocus dataset, Lopes-Lima et al. (2017b; Fig. 1) divided the Unionidae into seven subfamilies, two of which exhibit a Southeast Asian centre of diversity: (1) the Rectidentinae (=Contradentini+Rectidentini; 36 species, seven genera), which are exclusively distributed in Southeast Asia, and (2) the Gonideinae (=Chamberlainiini+Lamprotulini+Gonideini+Pse udodontini; 69 species, 15 genera), with a disjunct distribution in Asia, Europe, Africa and North America. The Gonideinae sensu Lopes-Lima et al. (2017b) were subsequently split by Bolotov et al. (2017a) into the Pseudodontinae (=Pseudodontini+Pilsbryoconchini) and the Gonideinae (=Gonideini) based on a three-locus dataset, which recovered a paraphyletic Gonideinae (Fig. 1). Paraphyly of the Gonideinae sensu LopesLima et al. (2017b) was also recovered in Huang et als (2019) trees, albeit with poor nodal support (Fig. 1). Finally, utilizing for the first time a genomic dataset of 596 nuclear loci, Pfeiffer et al. (2019) reintroduced the Pseudodontinae as the Pseudodontini in the Gonideinae and additionally included the Rectidentinae based on the consistent recovery and strong nodal support of this large monophyletic group (i.e. Gonideinae sensu Pfeiffer et al., 2019) (Fig. 1).

As an alternative to nuclear markers, mitochondrial DNA (mtDNA) has long been popular in population genetic and phylogenetic studies, owing to their generally high mutation rates and fast lineage sorting (Brown et al., 1979; Birky et al., 1983). The unionidan mitogenome is typical of the Metazoa in that it encodes 13 proteins that belong to four enzyme complexes of the respiratory chain, the small and large RNA subunits of the mitochondrial ribosomes and 22 tRNAs (Bernt et al., 2013a). However, the Unionidae, as well as at least two other unionidan families and a number of other bivalve groups, are distinctive in their doublyuniparental mode of mitochondria inheritance (Breton et al., 2009; Gusman et al., 2016). Female (F)-type mtDNA is transmitted through mothers to both male and female offspring, whereas male (M)-type mtDNA is transmitted through fathers only to male offspring and established in the germ line (Breton et al., 2007). M- and F-type mtDNA often exhibit nucleotide divergences of $>20 \%$ and thus provide two independent datasets for phylogenetic reconstructions (Breton et al., 2007). In addition, mitochondrial gene order has been identified as a valuable character in itself for supporting deep 

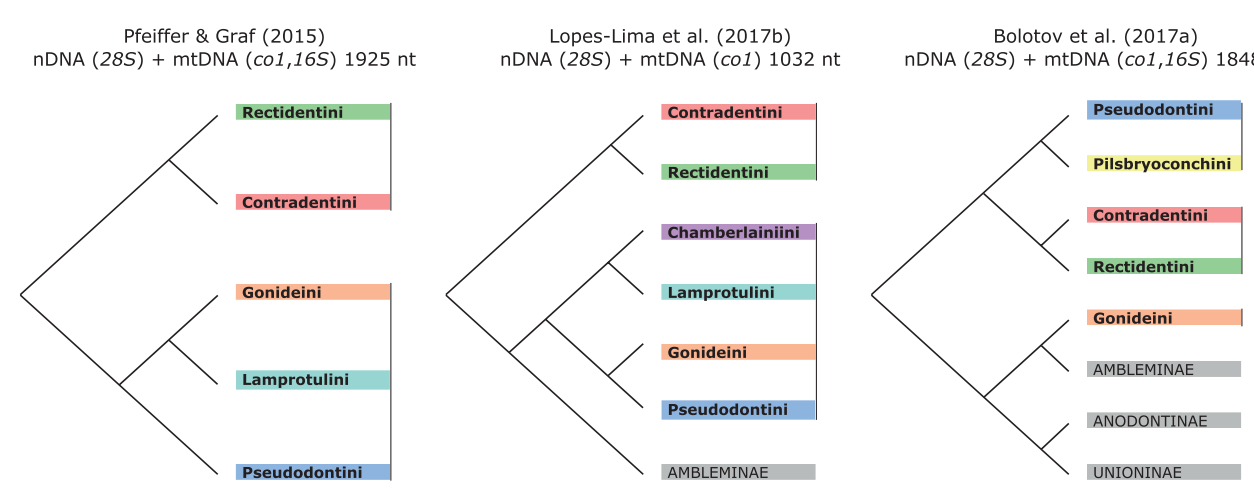

Froufe et al. (2020)
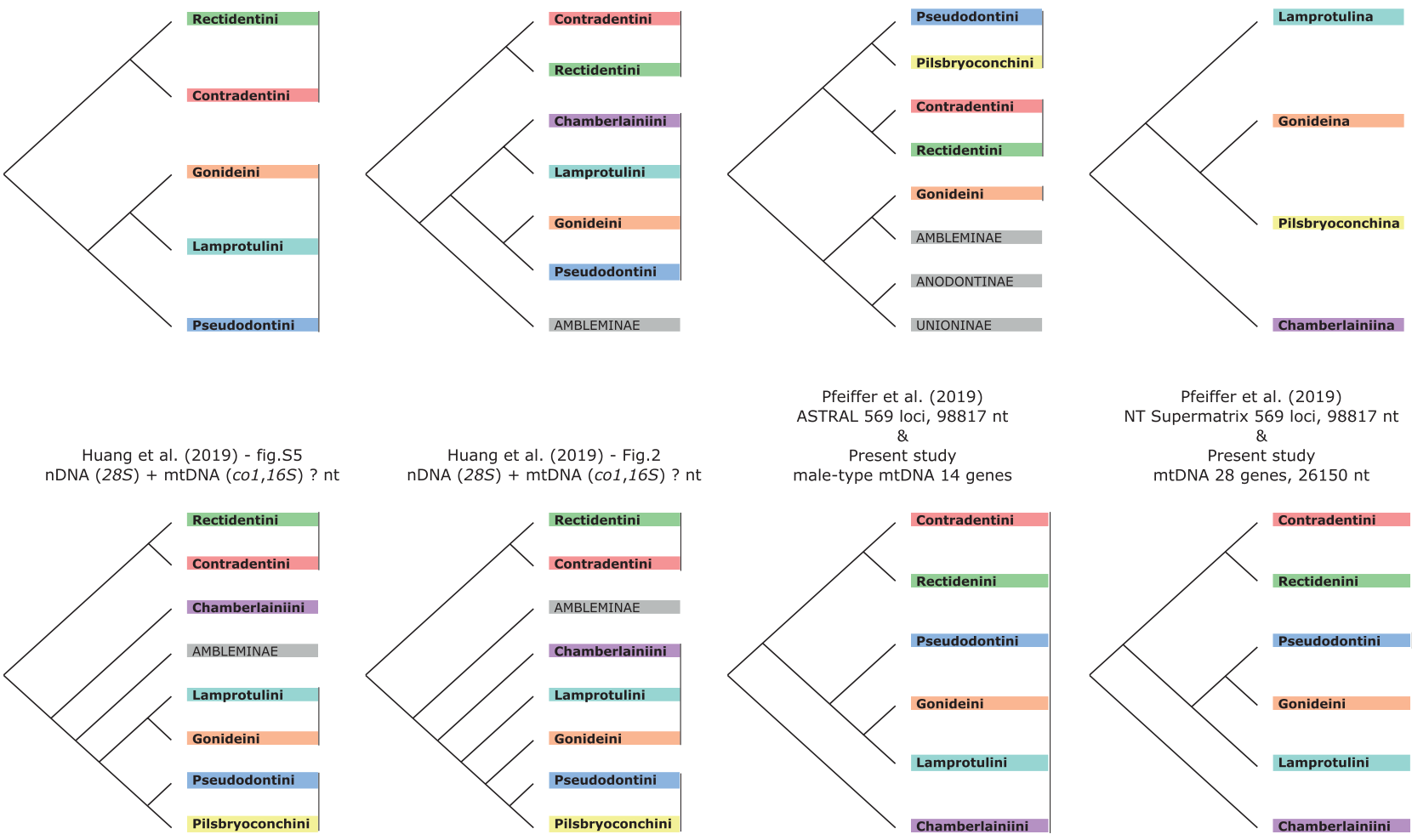

Figure 1. Recent multi-locus phylogenetic hypotheses on Gonideinae sensu Pfeiffer et al. (2019). Vertical bars indicate subfamilies recognized in respective publications. Note that Froufe et al. (2020) adopted a new systematic framework with three instead of two family-group levels, and thus, traditional tribes (ending -ini) are considered subtribes (ending -ina) in that study.

nodes (Lopes-Lima et al., 2017a). This was recently confirmed by Froufe et al. (2020), who, by combining M- and F-type mitogenomes for the first time, revealed that the Gonideinae sensu Lopes-Lima et al. (2017b) exhibits unique gene orders (i.e. UF2 and UF3) that are not found in any taxa outside this clade. To reflect more accurately the presence of several levels of highly divergent clades within the Unionidae, Froufe et al. (2020) additionally proposed a new systematic framework with three instead of two family-group levels (i.e. subfamilies, tribes and subtribes). Here, we use two levels of these higher taxa, i.e. subfamilies and tribes (see Table 1), because subtribes were erected within a few Unionidae tribes only (Froufe et al., 2020). As the phylogeny of Froufe et al. (2020) did not include any members of the Rectidentinae sensu Lopes-Lima et al. (2017b), hypotheses on the origin of this important Southeast Asian clade have never been tested using a mitogenome dataset.

In addition to a robust phylogenetic hypothesis, identifying the drivers of past diversification events requires knowledge of the timing (and place) of these evolutionary events. This information can be reconstructed through phylogenetic trees (or networks) that are time-calibrated using palaeogeographical events, the fossil record or external molecular clocks (themselves calibrated by either palaeogeographical events or fossils) (Wilke et al., 2009). Fossil-calibrated phylogenies have been constructed for the unionidan families Hyriidae (Grafet al., 2015), Unionidae (Bolotov et al., 2017a) and the Unionidae+Margaritiferidae (Froufeetal.,2020).Substitution (=mutation) rates vary considerably among genes, taxa and with time (Wilke et al., 2009). However, substitution rates have been calculated for only a small number of unionidan taxa and genes so far, all of which revealed comparatively low evolutionary rates. Froufe et al. (2016) and Araujo et al. (2016) determined almost identical mean rates for F-type COI, i.e. 2.7 and $2.5 \times 10^{-9}$ substitutions/site/ year (s/s/y) for Unio delphinus Spengler, 1793 / Unio foucauldianus Pallary, 1936 (Unionidae, Unioninae) and Potomida littoralis (Cuvier, 1798) (Unionidae, Gonideinae) respectively, using the Messinian Salinity Crisis (5.96 to 5.33 Mya) as their calibration point. Bolotov et al. (2016) obtained similar to slightly lower mean substitution rates for four pairs of margaritiferid 

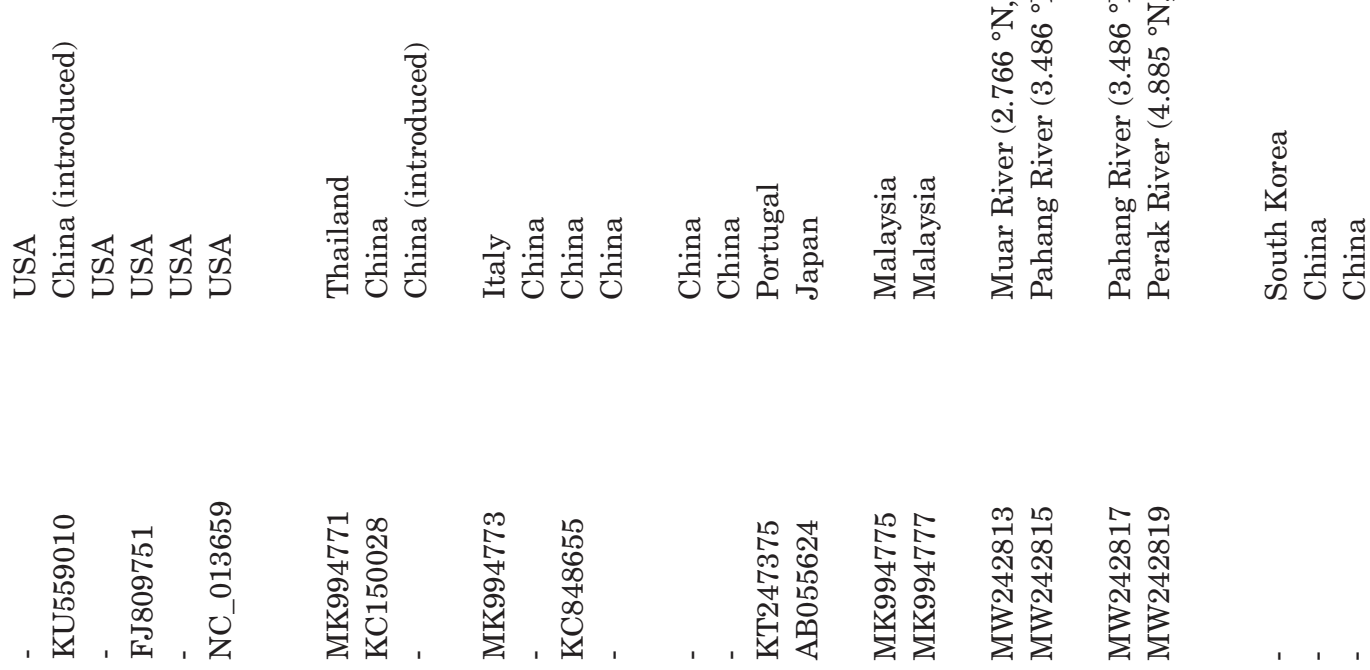

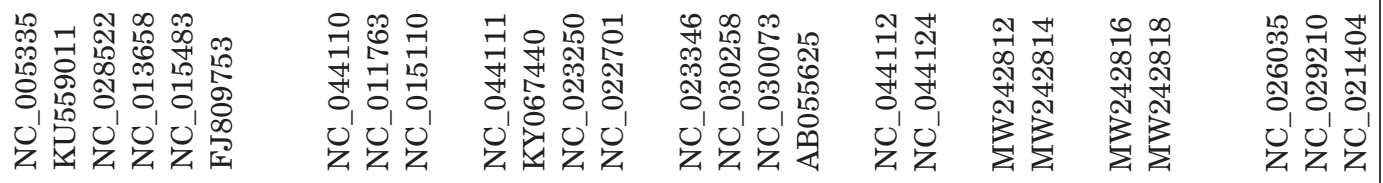

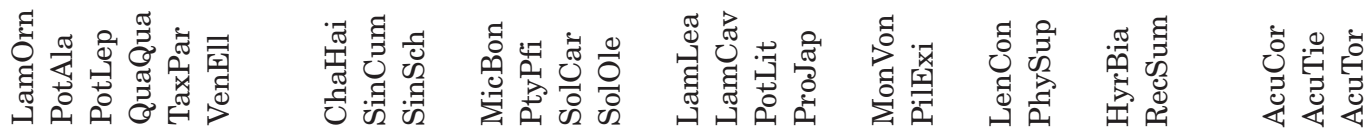

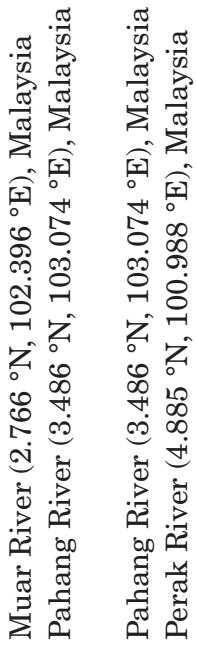

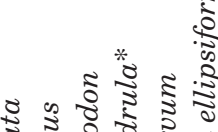

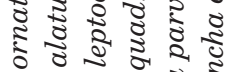

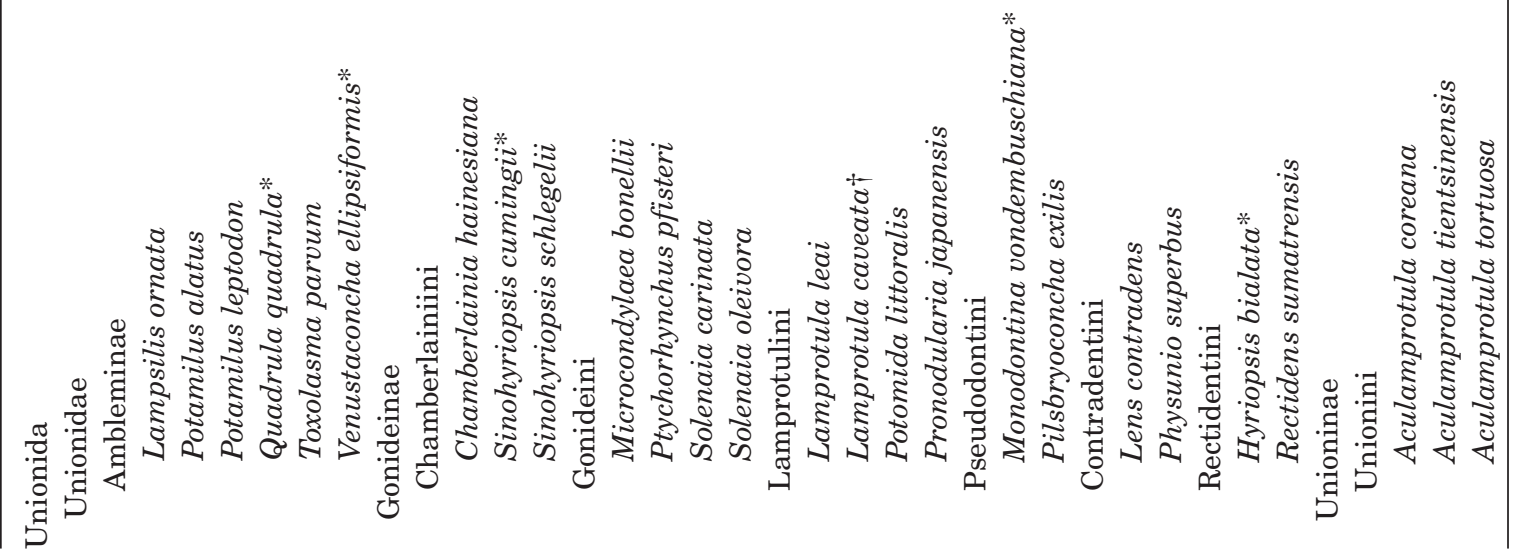




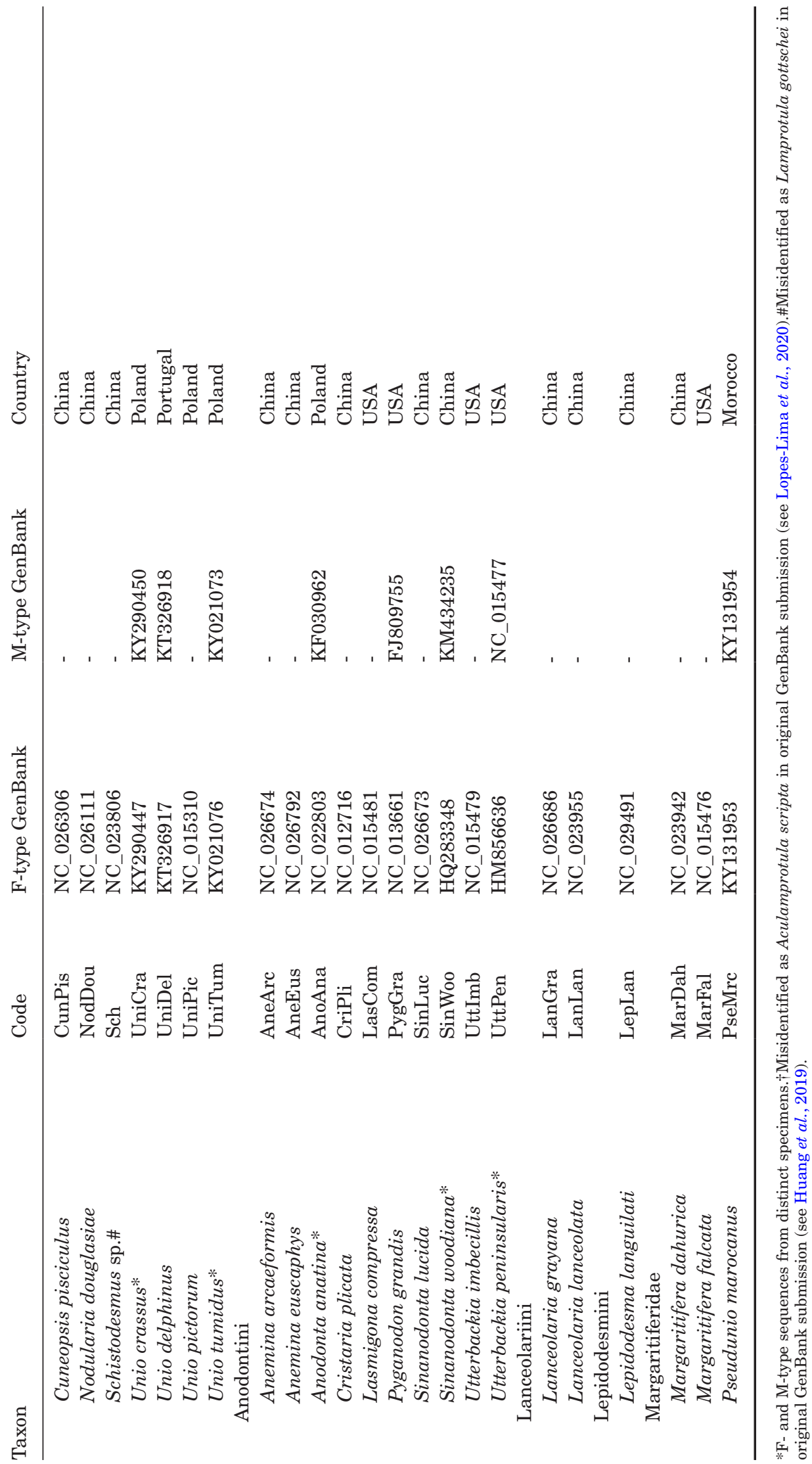


sister species, with an overall mean rate of $2.16 \times 10^{-9}$ $\mathrm{s} / \mathrm{s} / \mathrm{y}$ using fossil calibration points. In the same study, substitution rates for the margaritiferid $16 \mathrm{~S}$ are also provided, averaging $1.33 \times 10^{-9} \mathrm{~s} / \mathrm{s} / \mathrm{y}$, which exceed the rate for combined Unionidae and Margaritiferidae obtained by Lydeard et al. (1996) of around $0.50 \times 10^{-9}$ $\mathrm{s} / \mathrm{s} / \mathrm{y}$. These evolutionary rates are about two to ten times slower than for other molluscs (Stepien et al., 1999; Marko, 2002; Wilke et al., 2009), which has been attributed to the comparatively long generation times, longevity and low metabolic rates of freshwater mussels (Araujo et al., 2016; Bolotov et al., 2016). However, similarly low or even lower evolutionary rates have been recorded in coelacanths, anthozoan corals, salmonids, Acipenseriformes and Testudines [see Bolotov et al. (2016) and references therein].

This study aims to (1) test the validity of the Gonideinae sensu Pfeiffer et al. (2019) on the basis of two independent, complete mitogenomes (M-type, F-type and concatenated), for the first time including genera of the Contradentini+ Rectidentini; (2) infer implications on the evolutionary biogeography of this clade, including potential causes of divergence events, using a fossilcalibrated mitogenomic approach; and (3) estimate molecular substitution rates for all coding and two rRNA (12S and 16S) genes, plus the three most commonly used mitochondrial gene fragments (i.e. COI, 16S and ND1).

\section{MATERIAL AND METHODS}

\section{SAMPLING, DNA EXTRACTION, SEQUENCING, ASSEMBLY AND ANNOTATION}

One male specimen from each of two species of the Contradentini, i.e. Lens contradens (Lea, 1838), and Physunio superbus (Lea, 1843) and the Rectidentini, i.e. Rectidens sumatrensis (Dunker, 1852) and Hyriopsis bialata Simpson, 1990, respectively, was dissected for gonadal (to recover M-type mtDNA) and mantle (to recover F-type mtDNA) tissue collections. Specimens are deposited in the Museum of Zoology, University of Malaya (freshwater mussel collection lots \#12, 20, 46 and 59). DNA extractions of both tissues for each species were obtained using a standard high-salt protocol (Sambrook et al., 1989).

The genomic DNA was processed using Nexterabased library preparation (Illumina, USA) following the manufacturer's instructions. Quantification and size estimation of the library was then completed on a Bioanalyzer 2100 High Sensitivity DNA chip (Agilent, USA). The library was then normalized to $2 \mathrm{nM}$ and sequenced on a MiSeq Benchtop Sequencer $(2 \times 250 \mathrm{bp}$ paired-end reads) (Illumina, USA).

The mitochondrial genomes were reconstructed with MITObim (Hahn et al., 2013) using previously available
COI gene sequences for each species. Annotations were performed using MITOS (Bernt et al., 2013b), adjusting the final tRNAs gene limits of tRNA genes with ARWEN (Laslett \& Canbäck, 2008). In-house scripts (https://figshare.com/s/a756ef19cec8f65d506a) were also applied to adjust the mtDNA protein-coding limits given that MITOS often underestimates gene length.

All F- and M-type mitogenomes were visualized using GenomeVx (Conant \& Wolfe, 2008) and have been deposited in GenBank under the accession numbers MW242812-19.

\section{MitOCHONDRIAL PROTEIN-CODING GENES NUCLEOTIDE COMPOSITION ANALYSIS}

Nucleotide compositional bias of the sequenced mitogenomes was summarized as GC and AT skews according to the equations: $\mathrm{AT}$ skew $=(\mathrm{A}-\mathrm{T}) /(\mathrm{A}+\mathrm{T})$, GC skew $=(\mathrm{G}-\mathrm{C}) /(\mathrm{G}+\mathrm{C})($ Perna \& Kocher, 1995).

\section{PHYLOGENETIC INFERENCE}

\section{Datasets and sequence alignments}

To infer the phylogenetic relationships within the Unionida, we used the eight newly sequenced mitogenomes together with the Unionida mitogenomes available at NCBI (Table 1). In all phylogenetic analyses, we used the DNA sequences of all mtDNA protein-coding genes (PCG), except atp 8 and the gender-specific open reading frames [ $M$-orf, $H$-orf and $F$-orf (Breton et al., 2009)]. The sequences of the two rRNA genes were also included in all analyses. Each gene sequence was then aligned using the stand-alone version of GUIDANCE2 (Sela et al., 2015) with the MAFFT v.7 multiple sequence alignment algorithm (Katoh \& Standley, 2013). GUIDANCE builds a high-quality alignment and assigns confidence scores for each sequence, column or position in the alignment based on the guide-tree uncertainty. To build our single gene alignments we used the following GUIDANCE2 parameters: score algorithm: GUIDANCE2; bootstrap replicates: 100; sequence cutoff score: 0.0 (no sequence removal); column cut-off score: below 0.8 ; site masking score: below 0.6 (for codon and amino acids alignments) and below 0.8 (for the rRNA alignments). The resulting single gene alignments were finally concatenated into 12779 nucleotides (nt) for the F-type and $13370 \mathrm{nt}$ for the M-type (12 PCG plus 2 rRNA sequences). The resulting $\mathrm{M}+\mathrm{F}$ concatenated alignment spanned $26150 \mathrm{nt}$.

\section{Substitution model selection and partitioning schemes}

All concatenated dataset alignments were partitioned, and the best-fit substitution models selected with 
PartitionFinder2 using a greedy search approach, MrBayes model set and BIC selection criterion (Lanfear et al., 2017) (Supporting Information, Table S1).

\section{Phylogenetic analyses}

Phylogenetic inference applying a maximum likelihood (ML) methodology was performed to estimate the trees for all concatenated alignments using RAxML v.8.2.10 (Stamatakis, 2014) with 100 rapid bootstrap replicates and $20 \mathrm{ML}$ searches.

To infer the phylogeny with Bayesian methodology we used MrBayes v.3.2.7a (Ronquist et al., 2012). The alignment was partitioned according to the best scheme suggested by PartitionFinder. We applied a separate molecular substitution model for each partition. However, the prior probabilities of topology and branch lengths were linked across the partitions. Parameters were estimated as part of the analysis with four Markov chains incrementally heated with the default heating values. Each chain started with a randomly generated tree and ran for $1 \times 10^{7}$ generations with a sampling frequency of one tree for every 1000 generations. The resultant 10000 trees, after discarding the first $25 \%$ as burn-in, were combined in a $50 \%$ majority rule consensus tree. Two independent replicates were conducted and inspected for consistency. The log files were checked visually with Tracer v.1.7 for an assessment of the convergence of the MCMC chains and the effective sample size of parameters (Rambaut et al., 2018). The Effective Sample Size (ESS) values for all parameters from both BI phylogenies were recorded as $>750$. Tree topology differences were checked for significance with the KH- (Kishino \& Hasegawa, 1989), SH- (Shimodaira \& Hasegawa, 1999) and approximately unbiased (AU)tests (Shimodaira \& Hasegawa, 1999; Shimodaira, 2002 ) with 10000 bootstrap replicates all implemented in IQ-Tree 2 (Minh et al., 2020).

\section{CALIBRATED TIME PHYLOGENY}

The time-calibrated mitogenomic phylogenies were reconstructed in BEAST v.1.10.1 for F-type and M-type mtDNA separately based on two reliable fossil calibrations with exponential prior distributions (Supporting Information, Table S2), a lognormal relaxed clock and Yule speciation process as the tree prior (Suchard et al., 2018). Calculations were performed at the San Diego Supercomputer Center (SDSC, University of California, San Diego, USA) through the CIPRES Science Gateway (Miller et al., 2010). Three Margaritiferidae mitogenomes were used as outgroups for the F-type alignment, and one for the M-type alignment. Similar settings to each gene partition as in the MrBayes analyses were specified but using a simplified substitution model [HKY; see Bolotov et al. (2017a) for details]. Three replicate BEAST searches were conducted, each with 50000000 generations and a tree sampling every $1000^{\text {th }}$ generation. The log files were checked visually with Tracer v.1.7 for an assessment of the convergence of the MCMC chains and the effective sample size of parameters (Rambaut et al., 2018). The runs were compiled with LogCombiner v.1.10.1 (Suchard et al., 2018) using an appropriate burn-in depending on the start of convergence of MCMC chains in each run and an additional re-sampling every $5000^{\text {th }}$ generation. The ESS values for all parameters were recorded as $>300$. The maximum clade credibility tree was obtained from the post-burn-in trees using TreeAnnotator v.1.10.1 (Suchard et al., 2018).

\section{MoleCUlaR RATE CALCULATIONS AND ANALYSES}

After obtaining the age estimates in BEAST, for each node and each gene, average sequence divergence among subgroups of each node (always 2, as the tree was perfectly dichotomous) was calculated in MEGA-X (Kumar et al., 2018), using the maximum composite likelihood substitution model, with 1000 bootstraps, Gamma distributed rates among sites $(G=1)$ and pairwise deletion of gaps. Divergence values were then divided by the respective average age of the node, and $95 \%$ CI minimum and maximum ages, in order to obtain the average and $95 \%$ CI divergence rate per year, respectively. Average substitution rates per lineage $(\mu)$ were then obtained dividing those values by 2 . Rates were calculated in this way for each gene, fragment and the whole mitogenome.

To examine and quantify the effects of type (Mvs. F-type) and node age on divergence rates, we ran General Linear Models in R v.3.5.2 for each gene, fragment and the whole mitogenome, fitting "ln (divergence rate)" as a response variable, "type" as a factor with two levels, "ln (node age)" as a covariate, and the interaction of both terms. Non-significant terms $(P \geq 0.05)$ were sequentially dropped from the model.

The obtained substitution rates account for both synonymous and non-synonymous substitutions, and are therefore affected by the molecular mutation rate and the selective process. Rate variation among genes could therefore be linked to the strength of selection they are subject to. In order to better understand such constraints, we calculated the mean ratio of the number of non-synonymous substitutions per nonsynonymous site $\left(\mathrm{K}_{\mathrm{a}}\right)$ to the number of synonymous substitutions per synonymous site $\left(\mathrm{K}_{\mathrm{s}}\right)$ for each PCG and the whole coding portions of the mitogenome 
using DnaSP (Rozas et al., 2017). $\mathrm{K}_{\mathrm{a}} / \mathrm{K}_{\mathrm{s}}$ values $>1$ indicate positive (directional) selection, $<1$ negative (stabilizing) selection and 1 neutrality. Finally, we examined the relationship between the differences in F-type and M-type $\mu$ and $\mathrm{K}_{\mathrm{a}} / \mathrm{K}_{\mathrm{s}}$-ratios across the 13 PCGs through regression analysis.

\section{RESULTS}

\section{MITOGENOME CHARACTERISTICS AND GENE ORDER}

All of the eight sequenced mitogenomes include the 13 protein-coding genes (PCGs) typically found in metazoan mitochondrial genomes, the type-specific orf described for all Unionida mitogenomes with the DUI system and 22 transfer RNA (tRNA) and two ribosomal RNA (rRNA) genes (Fig. 2). The length of M-type mitogenomes is larger than the F-type as is usual in the Unionida, ranging from $16761 \mathrm{nt}$ in Hyriopsis bialata to $17282 \mathrm{nt}$ in Physunio superbus, while the F-type ranged from $15956 \mathrm{nt}$ in Lens contradens to $16057 \mathrm{nt}$ in Physunio superbus (Table 2; Fig. 2). The A+T content and GC and AT skews are similar across all sequenced species and types, averaging $62 \%, 0.38$ (+ strand) and -0.20 (+ strand), respectively (Table 2). Gene order of the mitogenomes for all four newly sequenced species was of Unionidae F-type 2 (UF2) for F- and Unionidae M-type 1 (UM1) for M-type mitogenomes (Lopes-Lima et al., 2017a).

\section{PHYLOGENETIC ANALYSES}

All phylogenies inferred in this study support the monophyly of the Gonideinae sensu Pfeiffer et al. (2019), and monophyly of the six gonideine tribes (Figs 1, 3,4). The only inconsistent result is that the Gonideini+Pseudodontini clade is not supported in M-type mtDNA phylogeny (Figs 1,3). However, topology tests of the concatenated $(\mathrm{M}+\mathrm{F})$ tree constrained with the separate M-type phylogeny was not significantly different to that of the unconstrained tree $(P>0.05$ in $\mathrm{KH}-, \mathrm{SH}-$ and AU-tests). The Chamberlainiini were consistently recovered as sister to other Gonideinae tribes in all phylogenies.

\section{FOSSIL-CALIBRATED PHYLOGENY}

The fossil-calibrated phylogeny of the complete F-type mitogenome dataset placed the split between the Ambleminae (North American) and Gonideinae+Unioninae (Western-North American+Eu ropean+Asian+African) in the middle Jurassic (mean age $=164$ Mya, 95\% HPD 155-185 Mya) as the most ancient divergence event within the family (Fig. 5; Supporting Information, Fig. S1A). The Gonideinae
(W-North American+European+Asian+African) and Unioninae (European+Asian+African) split in the late Jurassic (mean age $=152$ Mya, 95\% HPD $=138-$ 175 Mya), coinciding with a change in gene order in the most recent common ancestor (MRCA) of the Gonideinae. The Chamberlainiini (Southeast Asian) split from the rest of the Gonidaeinae in the early Cretaceous (mean age $=142$ Mya, 95\% HPD $=126-$ 164 Mya), followed by evolution of a new gene order in the MRCA of Chamberlainia hainesiana (Lea, 1856). The clades Contradentini+Rectidentini (Southeast Asian) and Lamprotulini+Pseudodontini+Gonide ini (W-North America, Europe+Asia) split from each other in the early Cretaceous (mean age $=125 \mathrm{Mya}$, $95 \%$ HPD $=106-147$ Mya). The tribes Contradentini and Rectidentini (both Southeast Asia-Indo-BurmaSundaland) split from each other in the late Cretaceous (mean age $=79$ Mya, 95\% HPD $=58-101$ Mya $)$. The crown groups of most recent tribes likely originated between 64 and $37 \mathrm{Mya}$, i.e. since the Cretaceous (during the Palaeocene and Eocene). In contrast, the tribe Chamberlainiini had a more ancient crown group originating near the Albian-Cenomanian boundary (mean age $=103 \mathrm{Mya}, 95 \% \mathrm{HPD}=72-132 \mathrm{Mya}$ ).

\section{MUtATION RATES AND $\mathrm{K}_{\mathrm{A}} / \mathrm{K}_{\mathrm{S}}$}

Mean substitution rates $(\mu)$ per mitochondrial gene ranged from $1.14(\mathrm{rrnS})$ to 6.77 (atp8), and 1.42 $(r r n S)$ to $7.71(a t p 8) \mathrm{s} / \mathrm{s} / \mathrm{y} \times 10^{-9}$ in F-type and M-type, respectively (Table 3; Fig. 6A). Atp 8 thereby exhibited by far the highest $\mu$ in both $\mathrm{F}$ - and M- type mitogenomes, followed by nad 2-6. The lowest $\mu$ were recorded for the two ribosomal genes and the cytochrome $c$ oxidase subunits with the exception of type M-cox2, which exhibits a particularly variable extension.

Substitution rates across the whole mitogenome were strongly and significantly affected by 'type' and 'node age', which explained 25 and $35 \%$ of the variation, respectively (Table 3), with rates being higher in M-type mtDNA and decreasing with node age (Fig. S1B). Similarly, highly significant effects of 'type' and 'node age' on $\mu$ were found for 12 of the 15 mtDNA genes. Exceptions were atp8 (no effect of 'type' and 'node age') and nad $4 l$ and nad6 (no effect of 'node age'). Across the whole mitogenome, M-type $\mu$ was $31 \%$ higher than F-type $\mu$ (Table 3 ). This difference was lowest in atp8 (13\%), cob (22\%) and the two ribosomal genes (17 and $23 \%$, respectively), and highest in cox 2 (61\%), nad6 (51\%), nad4l (49\%) and nad3 (46\%). Absolute differences in M-type and F-type $\mu$ ranged from 0.3 (for ribosomal genes) and 0.5 (for cox1) to 2.1 (for nad6) s/s/y $\times 10^{-9}$ (Table 3; Fig. 6B).

Mean $\mathrm{K}_{\mathrm{a}} / \mathrm{K}_{\mathrm{s}}$ per PCG ranged from $0.12(\operatorname{cob}, \operatorname{cox} 1)$ to 0.51 (atp8) in M-type and 0.02 (cox1) to 0.39 (atp8) 

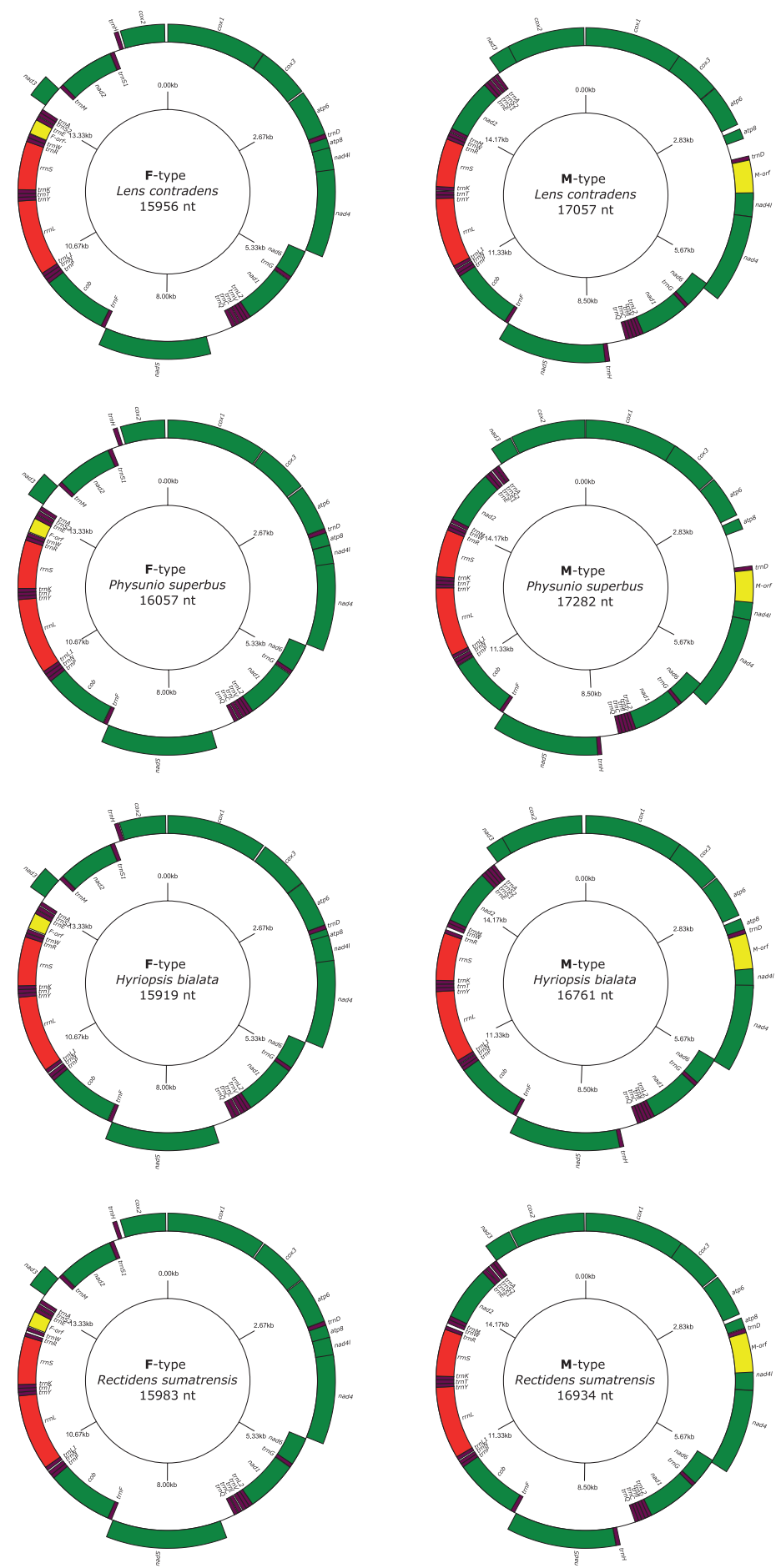

Figure 2. Gene maps of the F- and M-type mitochondrial genomes of Lens contradens, Physunio superbus, Hyriopsis bialata and Rectidens sumatrensis. Genes positioned inside the circle are encoded on the heavy strand, and genes outside the circle are encoded on the light strand. Colour codes: small and large ribosomal RNAs (red); transfer RNAs (purple); $M$-orf, F-specific open reading frame (yellow); $M$-orf, M-specific open reading frame (yellow); protein-coding genes (green). 


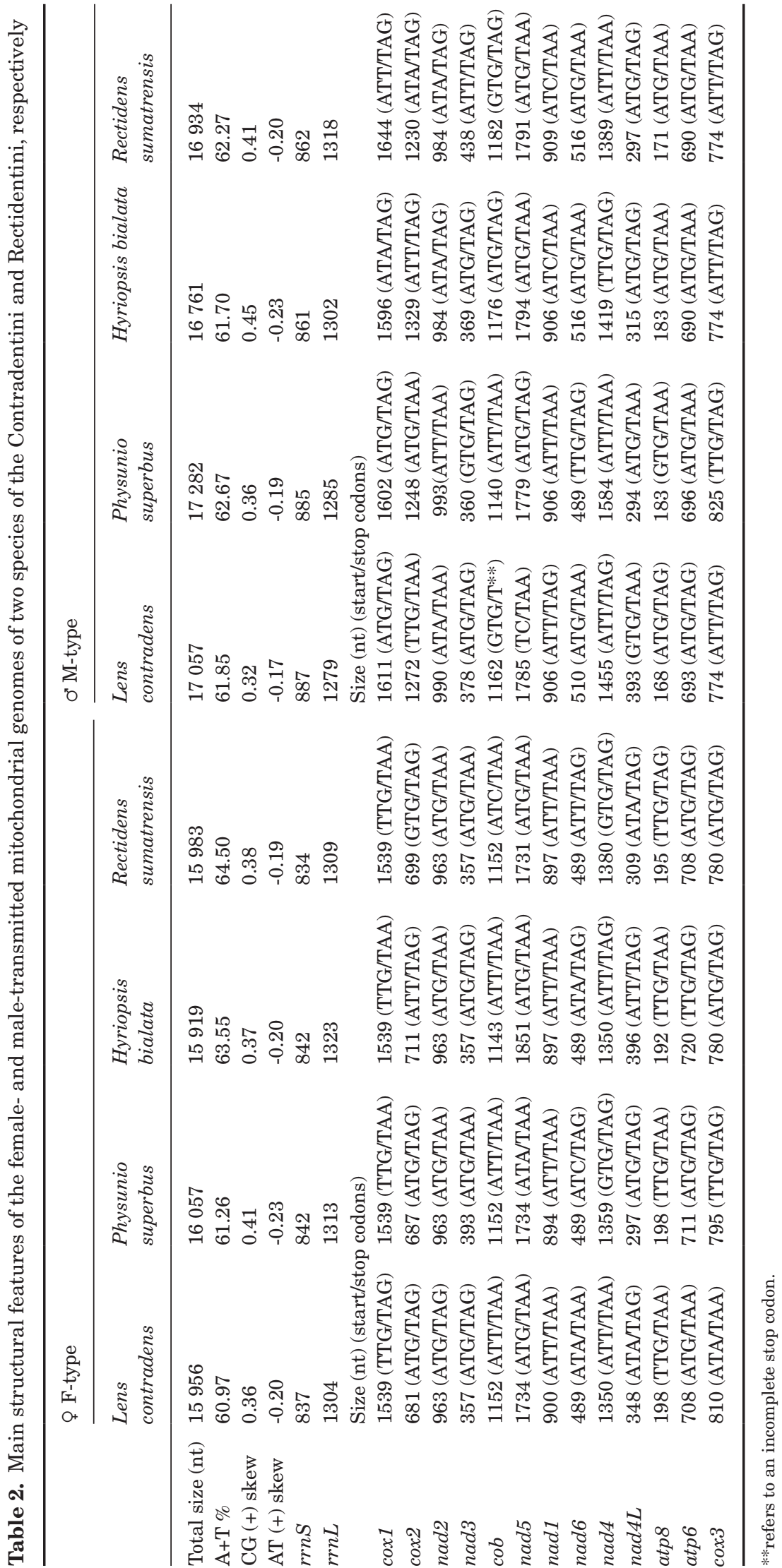




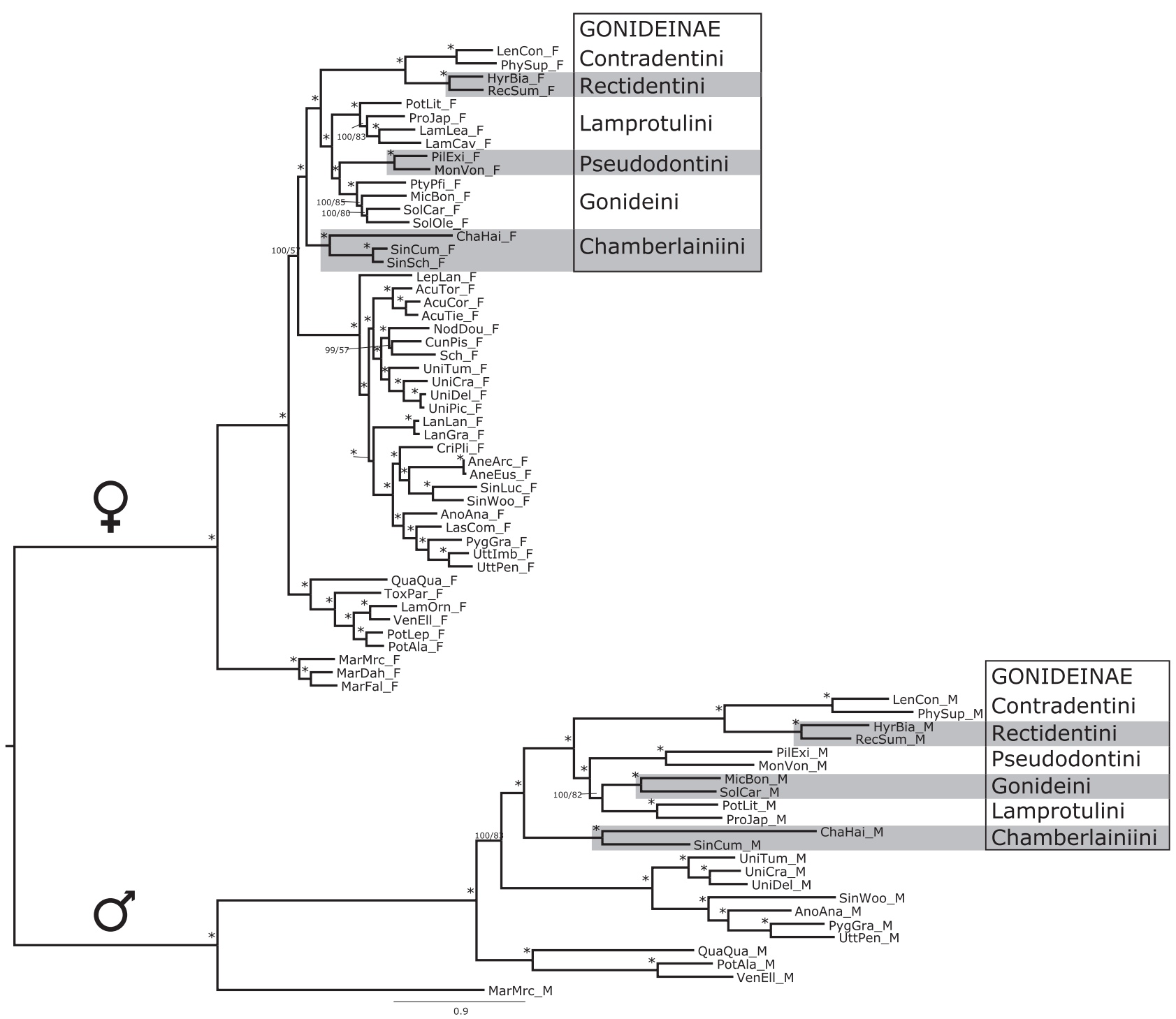

Figure 3. Phylogenetic tree of the Unionidae+Margaritiferidae estimated from 14 concatenated individual mtDNA gene sequences (12 protein-coding and 2 rRNA genes). Values for branch support above each node represent Bayesian posterior probabilities percentage/maximum likelihood bootstrap support. *Supported values $\geq 95$ are represented by an asterisk.

in F-type mtDNA (Table 3 ). $\mathrm{K}_{\mathrm{a}} / \mathrm{K}_{\mathrm{s}}$ was significantly positively correlated with $\mu$, explaining $82 \%$ of the variation in $\mu\left(\mathrm{F}_{1,24}=110.2, P<0.0001\right.$; Fig. $\left.6 \mathrm{~A}\right)$. In addition, M-type $\mathrm{K}_{\mathrm{a}} / \mathrm{K}_{\mathrm{s}}$ was consistently and significantly higher than $\mathrm{F}$-type $\mathrm{K}_{\mathrm{a}} / \mathrm{K}_{\mathrm{s}}$ across PCGs (ANOVAs: $P<0.001$ ). This difference between M-type and $\mathrm{F}$-type $\mathrm{K}_{\mathrm{a}} / \mathrm{K}_{\mathrm{s}}$ was particularly pronounced in nad3, nad4l and nad2, and particularly small in $c o b$ and nad1 (Fig. 6B). In addition, there was a significant relationship between the difference in $\mu$ and difference in $\mathrm{K}_{\mathrm{a}} / \mathrm{K}_{\mathrm{s}}$ between M-type and $\mathrm{F}$-type PCGs $\left(\mathrm{F}_{1,11}=5.728, P=0.0357\right)$, with the difference in $\mathrm{K}_{\mathrm{a}} / \mathrm{K}_{\mathrm{s}}$ explaining $34 \%$ of the variation in the difference in $\mu$ (Fig. 6B).

\section{DISCUSSION}

\section{PHYLOGENy}

Our mitogenomic phylogenetic hypotheses of the Gonideinae are congruent with those recovered on the basis of a nuclear genomic dataset by Pfeiffer et al. (2019). This recovers the Ambleminae as sister to the remaining, sampled unionid subfamilies and the Gonideinae as a monophyletic group, and is in contrast to most previously published phylogenies based on two- or three-locus datasets, which recovered a paraphyletic Gonideinae with respect to at least the Ambleminae (Fig. 1). The consistency of results across nuclear markers and mitogenomic datasets 


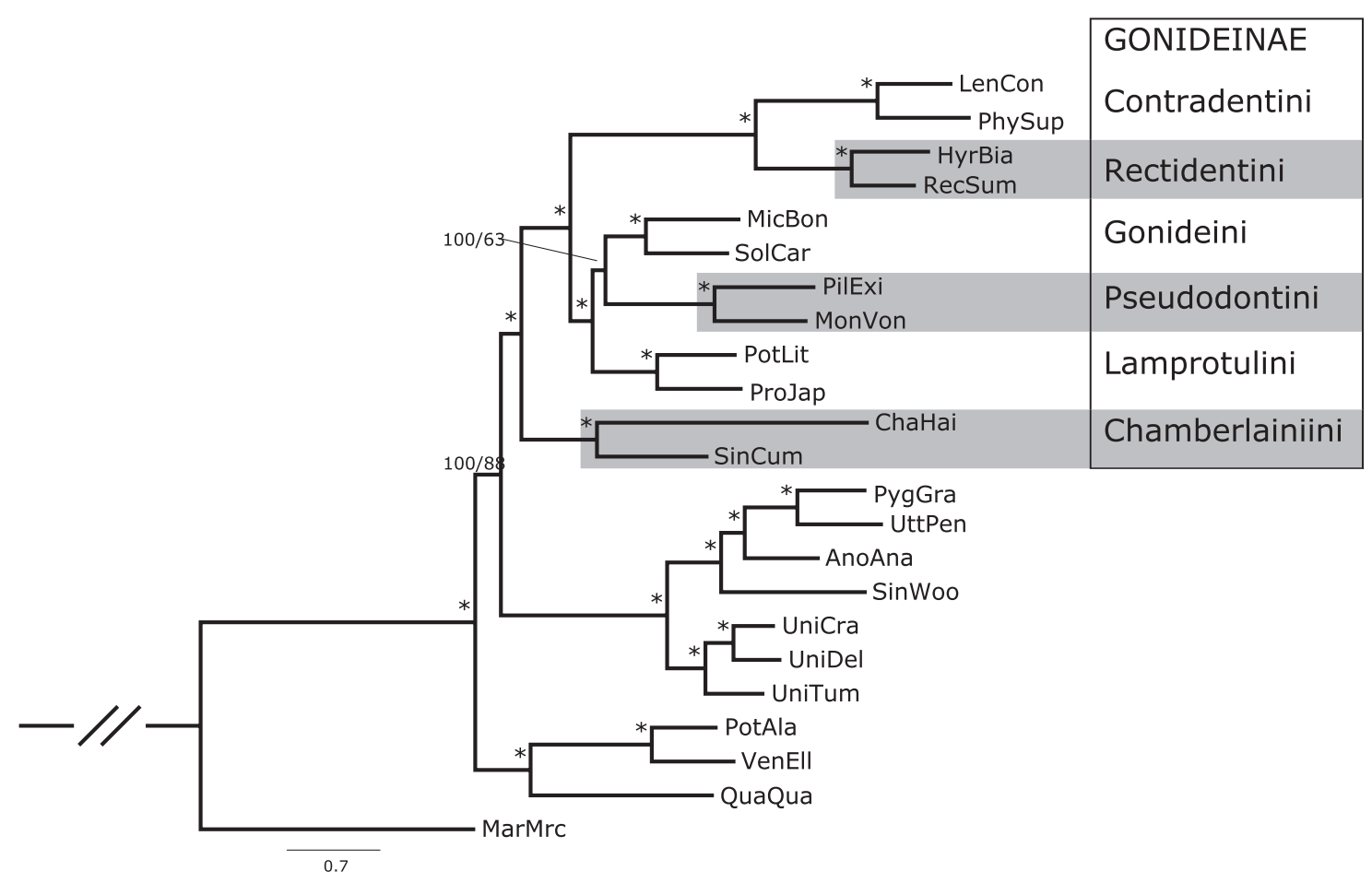

Figure 4. Phylogenetic tree of the Unionidae+Margaritiferidae estimated from 28 concatenated individual mtDNA gene sequences, i.e. 14 from female-type (12 protein-coding and 2 rRNA genes) and 14 (12 protein-coding and 2 rRNA genes) from male-type mitochondria. Values for branch support above each node represent Bayesian posterior probabilities percentage/ maximum likelihood bootstrap.

adds confidence to this phylogenetic hypothesis of the Gonideinae. In addition, the hypothesis is congruent with patterns in F-type mtDNA gene order, with the ancestral Unionidae order UF1 being retained in the Ambleminae and (at least) the Unioninae, and evolution of UF2 in the common ancestor of the Gonideinae and subsequent evolution of the UF2 variant UF3 in (at least) Chamberlainia hainesiana. If, for example, Lopes-Lima et als (2017b) or Huang et als (2019; Fig. 2) hypotheses were assumed, either UF1 or UF2 would have evolved independently twice (e.g. UF1 in the Unioninae and Ambleminae), which would represent a less parsimonious situation.

\section{EVOLUTIONARY BIOGEOGRAPHY}

Our updated fossil-calibrated phylogeny revealed a Mesozoic origin of the Unionidae, placing its crown group in the early Jurassic. These results are in full agreement with earlier studies of divergence patterns within this family based on multiple fossil calibrations (Bolotov et al., 2017a, b). Furthermore, the ages inferred from our fossil-calibrated phylogeny align with those of Bolotov et al. (2020), which were reconstructed using an external mutation rate, i.e. of Froufe et al. (2016).
Here, the Contradentini+Rectidentini was recovered as an ancient clade (mean age $=79 \mathrm{Mya}$ ), supporting the hypothesis of a late Cretaceous origin of Southeast Asian freshwater mussel fauna (Bolotov et al., 2017a, b). We found that the crown groups of most gonideine tribes likely originated during the Palaeocene and Eocene. These key divergence events in the subfamily roughly coincide with a warm and humid climatic episode in the early Palaeogene (Wing et al., 2005; Gingerich, 2006), when mid-latitude mean annual air temperatures reached $23-29{ }^{\circ} \mathrm{C}$ (Naafs et al., 2018). The origin of the majority of gondeine tribes could be explained by long-distance dispersal triggered by favourable climatic and hydrological conditions in the early Palaeogene (Carmichael et al., 2017) followed by diversification processes caused by range fragmentation during subsequent cold and dry periods (Feng et al., 2013). Evidence for rapid range expansion during the Palaeocene-Eocene Thermal Maximum has been found in several other groups, including reptiles (Bourque et al., 2015), mammals (Smith et al., 2006; Burger, 2012) and plants (Wing et al., 2005; Wing \& Currano, 2013). A similar but younger "evolutionary burst" roughly coinciding with the Miocene Climatic Optimum, a warm and humid period, was discovered in genus-level clades of the radicine pond snails 


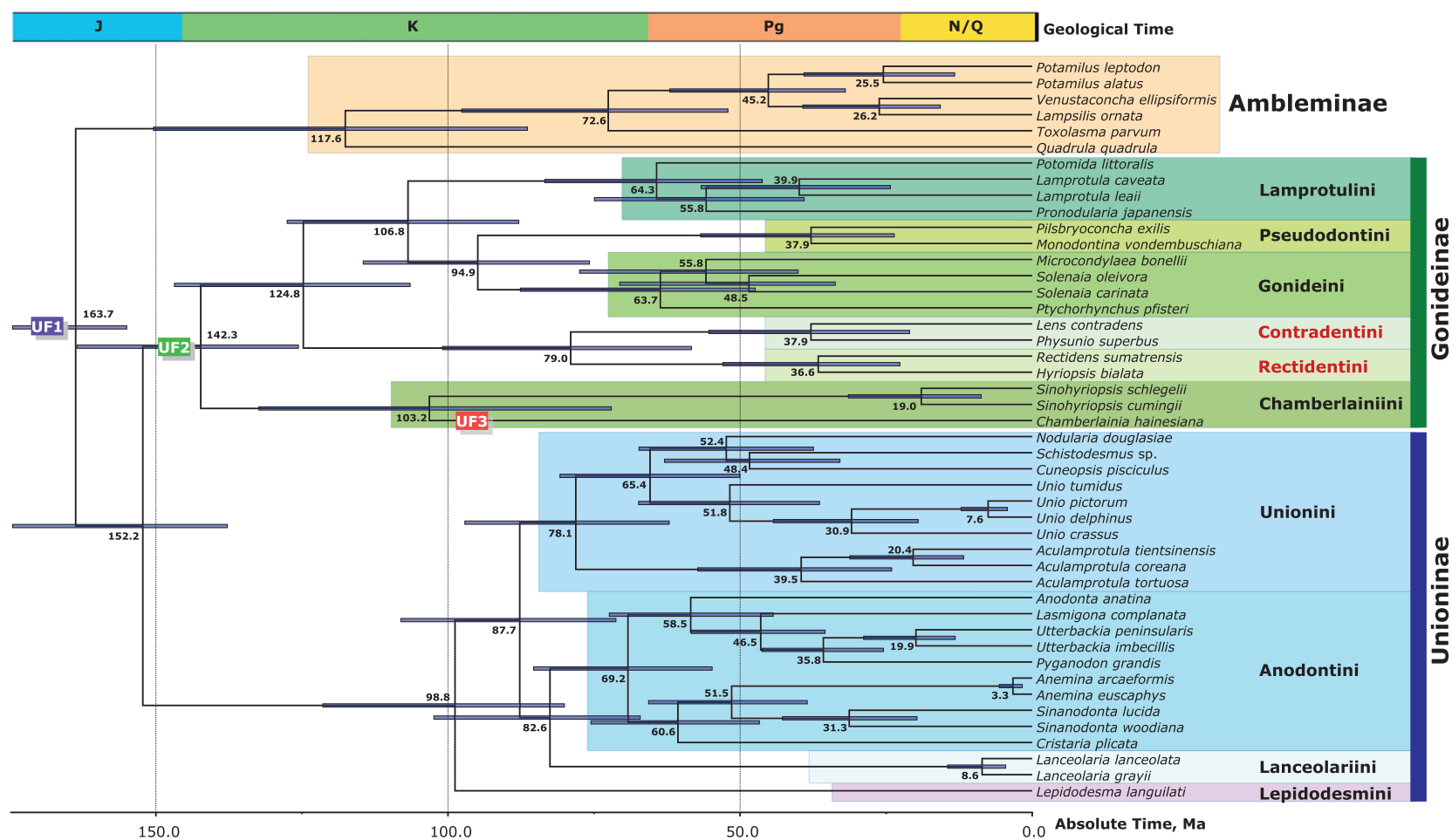

Figure 5. Fossil-calibrated ultrametric chronogram of the Unionidae calculated under a lognormal relaxed clock model and a Yule process speciation implemented in BEAST v.1.10.1 and obtained for the complete F-type mitogenome data set. The newly sequenced tribe-level taxa are coloured red. An outgroup sample (Margaritiferidae) has been removed for better visualization (but see original BEAST tree in Supporting Information, Fig. S1A). Bars indicate 95\% confidence intervals of the estimated divergence times between lineages (Mya). Black numbers near nodes are mean ages (Mya). Colour labels indicate the F-mtDNA gene order (UF1, UF2, and UF3). Stratigraphic chart according to the International Commission on Stratigraphy v.2018/08 (www.stratigraphy.org). Abbreviations: J, Jurassic; K, Cretaceous; N, Neogene; Pg, Palaeogene; Q, Quaternary.

(Lymnaeidae) (Aksenova et al., 2018). The authors suggested that subsequent aridification periods led to fragmentation of continuous ranges and thus radiation in multiple radicine lineages in suitable refugia.

\section{VARIATION IN MUTATION RATES}

\section{Comparison with previously published substitution rates and potential applications}

Substitution rates determined in this study are comparable to those already available for other Unionida groups (Lydeard et al., 1996; Araujo et al., 2016; Bolotov et al., 2016; Froufe et al., 2016). The mean substitution rate for the (most commonly used mtDNA fragment) F-type COI of $1.6 \times 10^{-9} \mathrm{~s} / \mathrm{s} / \mathrm{y}$ reported here lies in between those reported for four margaritiferid species pairs (Bolotov et al., 2016) and two unionid species (pairs) (Araujo et al., 2016; Froufe et al., 2016). The rate for F-type $16 \mathrm{~S}$ of $0.83 \times 10^{-9} \mathrm{~s} / \mathrm{s} / \mathrm{y}$ is slightly slower than those reported for the Margaritiferidae (Bolotov et al., 2016) but exceeds those inferred from the combined Unionidae and Margaritiferidae (Lydeard et al., 1996). It was expected that the Margaritiferidae may share slower substitution rates because of their generally longer generation times and slower metabolic rates compared to the Unionidae (Bolotov et al., 2016), but this supposition was not supported by our novel results.

Molecular clocks can overcome some gaps in the fossil record by producing informative date estimates for fossil-poor evolutionary events or those for which available fossil data have limited power (e.g. due to the lack of reliable distinguishing features for morphological identification) (Donoghue \& Yang, 2016). Fields of application include: (1) estimating clade ages in phylogenetic and phylogeographic studies when fossil and palaeobiogeographic data are not available; (2) studying complex geological histories; and (3) validating time-estimations of geological and tectonic events, such as the separation of land masses or the formation and evolution of river basins (Pennington et al., 2004; Ketmaier et al., 2006; 


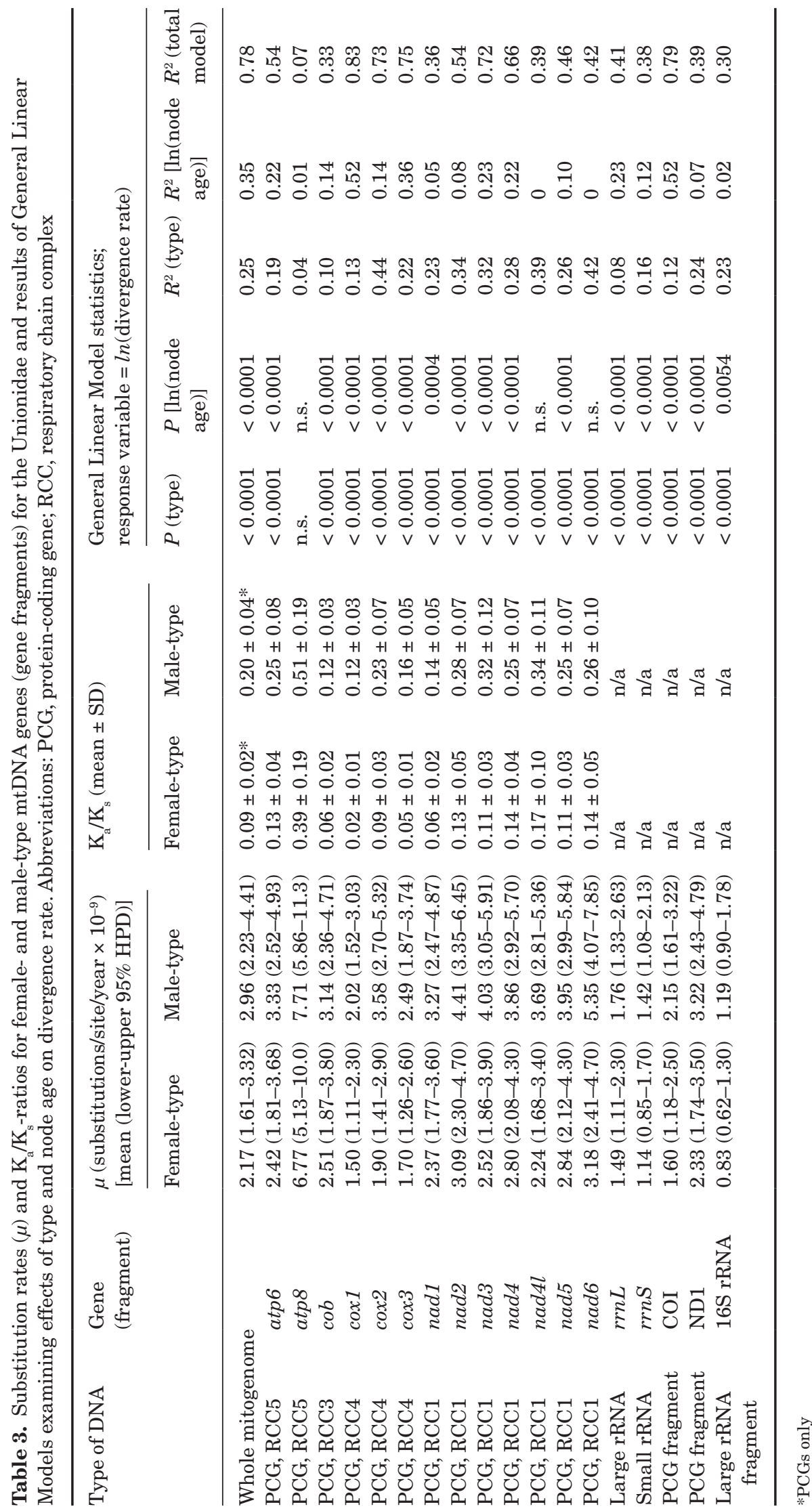



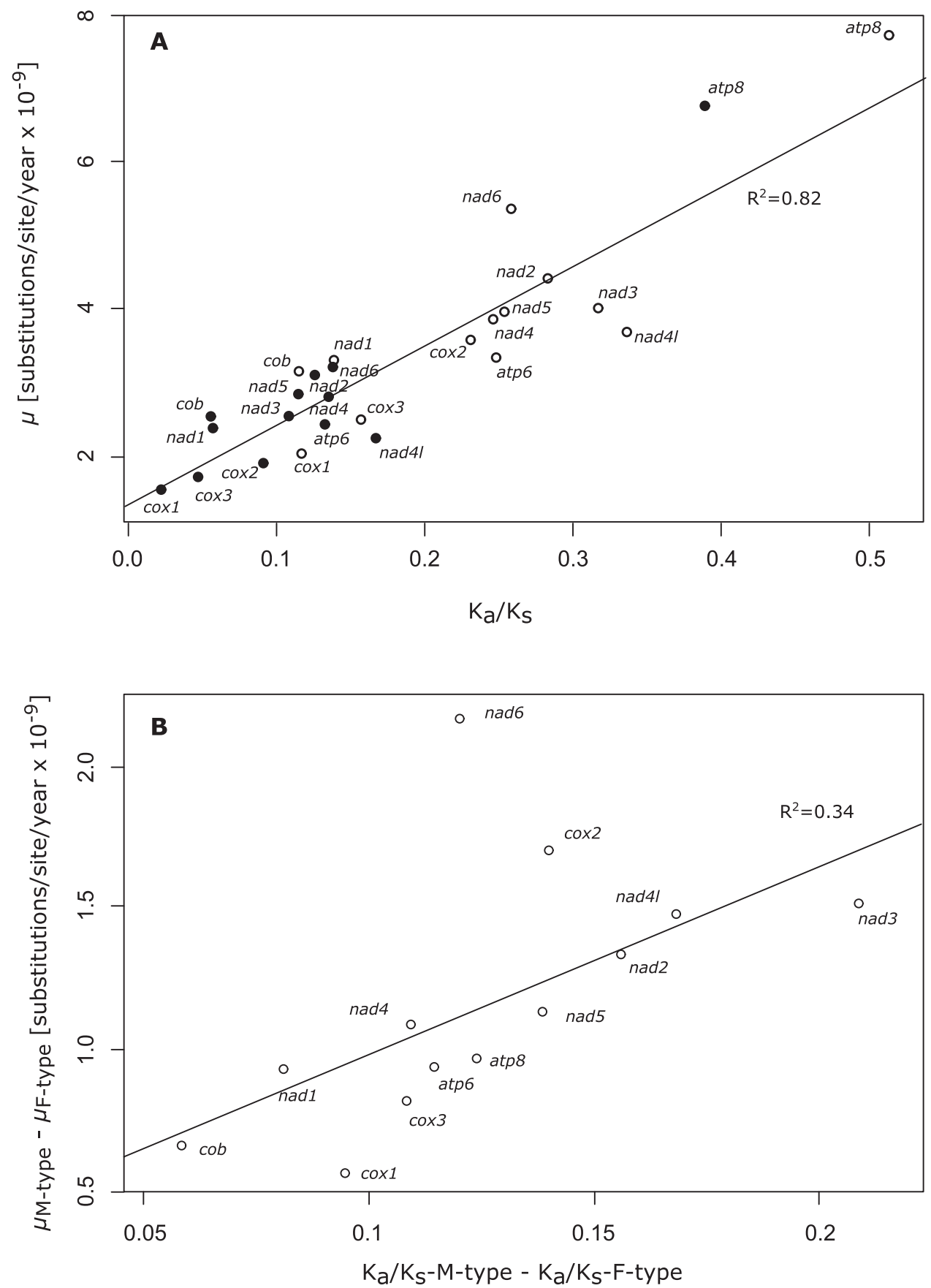

Figure 6. Relationship between (A) mean $\mathrm{K}_{\mathrm{a}} / \mathrm{K}_{\mathrm{s}}$ and substitution rate $(\mu)$ per female-type (full circles) and male-type (empty circles) mtDNA protein-coding gene; and (B) differences between male- and female-type $\mathrm{K}_{\mathrm{a}} / \mathrm{K}_{\mathrm{s}}$ and $\mu$ per proteincoding mtDNA gene.

Roxo et al., 2014; Chen et al., 2016). However, careful selection of the substitution rate applied in a given context is crucial as effectiveness and accuracy of a given rate varies depending on the time scale of the event. For example, applying the power test by Wilke et al. (2009) and a type II error of 0.05 , data variability in COI ( 710 nt), ND1 ( 830 nt) and 16S ( 570 nt) is insufficient to reliably date phylogenetic events that are younger than 2.6, 1.1 and 6.3 Mya, respectively; at least when used independently. The matter is further complicated by time dependency and incomplete coalescence in shallower phylogenetic depths. 
Possible rate heterogeneity across branches should be considered (e.g. using an uncorrelated clock model in phylogenetic estimation), which is why we performed rate calculations for every node in the tree, and provide a rate confidence interval that should be used to guide future applications (Table 3; Supporting Information, Fig. S2). Our dataset allows ageing of any node within the unionid phylogeny and therefore, application at various taxonomic levels, as substitution rates can be calculated for any given node age and gene (fragment) using the regression equations given in Supporting Information (Fig. S2).

\section{Variation across genes}

In comparison to nuclear DNA, mutations in mtDNA are rapidly accumulated, which has been attributed to an error-prone DNA repair system, the lack of protective histone-like protein, exposure of single-strand intermediates during mitochondrial replication, and/or exposure to oxidative damage (Castellana et al., 2011; Bernt et al., 2013a; and references therein). In addition, recombination is usually absent, and the genetically effective population size of animal (F-type) mtDNA is estimated to be only a quarter that of nuclear DNA (nDNA) due to (doubly)-uniparental inheritance (DUI) and haploidy (Birky et al., 1983; Castellana et al., 2011); effective population size of M-type DNA being even smaller due to fewer mtDNA copies in the sperm compared to oocyte (Zouros, 2013). However, loss of functionality of mtDNA, including genes encoding for protein complexes that play vital roles in aerobic respiration, is prevented predominantly by strong negative selection, removing non-synonymous deleterious mutations (Castellana et al., 2011). In addition, evidence for positive selection in mtDNA has been found for some genes and taxa (Bazin et al., 2006; Oliveira et al., 2008; Śmietanka et al., 2010).

In accordance with previous studies on other taxa, our dataset showed that substitution rates vary considerably among unionid mtDNA genes. As expected, rRNA fragments evolved much more slowly, which has been shown in various taxa before and partly attributed to high AT content (Brown, 1985; DeSalle et al., 1987). With respect to PCGs, substitution rates of atp 8 exceeded those of $\operatorname{cox} 1$ by a factor of about 20 in F-mtDNA and a factor of 5 in M-mtDNA, values that are comparable to those of Śmietanka et al. (2010) on Mytilus spp. To a large degree, this variation in substitution rates among PCGs appears to be associated with a variation in negative selection pressure as indicated by the strong positive correlation between $\mathrm{K}_{\mathrm{a}} / \mathrm{K}_{\mathrm{s}}$ and $\mu$ of our dataset. Strongly relaxed negative selection in atp 8 has been observed in several other taxa, including whitefish, vertebrates and Mytilus spp. (Śmietanka et al., 2010; Castellana et al., 2011; Jacobsen et al., 2016). Sun et al. (2017) suggested that negative selection of atp 8 was already strongly relaxed in the most recent common ancestor of all bivalves and that the gene appears to have been lost in several marine bivalve species. However, positive directional selection or the Compensatory-Draft Feedback (CDF) process [i.e. positive selection of compensatory mutations for mild-deleterious mutations fixed by e.g. genetic drift (Oliveira et al., 2008)] may also play a role as has been shown for atp 8 and other PCGs in, for example, mammals (da Fonseca et al., 2008), parasitic wasps (Oliveira et al., 2008), billfish (Dalziel et al., 2006) and Mytilus spp. (Śmietanka et al., 2010).

\section{Variation between mtDNA types}

As expected and observed in a number of previous studies (e.g. Liu et al., 1996; Hoeh et al., 2002), our study confirmed that the unionid M-type mitogenome evolves faster than the F-type mitogenome (overall by $31 \%$ ). This has been attributed to relaxed negative selection in M-type mtDNA and the CDF (Burzyński et al., 2017 and references therein), which is at least partly supported by a significant association between the difference in M-type and F-type substitution rates and difference in M-type and F-type $\mathrm{K}_{\mathrm{a}} / \mathrm{K}_{\mathrm{s}}$ in our dataset. That said, again, positive selection may play a considerable role, especially in the $\sim 550 \mathrm{nt}$ extension in M-type cox2 (Chapman et al., 2008).

\section{CONCLUSION}

Our mitogenomic phylogeny confirmed the validity of the Gonideinae sensu Pfeiffer et al. (2019), which are characterized by a synapomorphic mitogenome gene order (UF2). Fossil-calibration of this phylogeny, which was in line with one constructed using an external mutation rate (Bolotov et al., 2020), further revealed novel insights into the evolutionary history and biogeography of the Unionidae, including evidence for rapid range expansion of several clades within the Unionidae during the Palaeocene-Eocene Thermal Maximum and origin of the Southeast Asian Rectidentini in the late Cretaceous. Most importantly, the set of substitution rates of 30 mtDNA genes generated in our study will provide an important basis for future studies aiming to unravel the evolutionary history and biogeography of the Unionidae. Considering their exceptionally high levels of diversity, endemism and threat, particular focus should thereby be put on tropical freshwater mussels, including the Parreysiinae and Bornean endemic genera (Zieritz et al., 2018a, 2020). 


\section{ACKNOWLEDGEMENTS}

This research was developed under ConBiomics: the missing approach for the Conservation of Freshwater Bivalves Project No. NORTE-01-0145-FEDER-030286, co-financed by COMPETE 2020, Portugal 2020, and the European Union through the ERDF, and by the Portuguese Foundation for Science and Technology (FCT) through national funds, and Strategic Funding UIDB/04423/2020 and UIDP/04423/2020. FCT also supported A.G.S. (SFRH/BD/137935/2018) and S.V. (UID/AGR/04033/2019).A.Z. was supported by an Anne McLaren Research Fellowship from the University of Nottingham. I.N.B. was supported by the Ministry of Science and Higher Education of Russia (Project No. AAAA-A18-118012390161-9 and Project No. FSRU2020-0007) and the Russian Scientific Fund (Project No. 19-04-00066).

\section{REFERENCES}

Aksenova OV, Bolotov IN, Gofarov MY, Kondakov AV, Vinarski MV, Bespalaya YV, Kolosova YS, Palatov DM, Sokolova SE, Spitsyn VM, Tomilova AA, Travina OV, Vikhrev IV. 2018. Species richness, molecular taxonomy and biogeography of the radicine pond snails (Gastropoda: Lymnaeidae) in the Old World. Scientific Reports 8: 11199.

Araujo R, Buckley D, Nagel K-O, Machordom A. 2016. Potomida littoralis (Bivalvia, Unionidae) evolutionary history: slow evolution or recent speciation? Zoological Journal of the Linnean Society 179: 277-290.

Bazin E, Glémin S, Galtier N. 2006. Population size does not influence mitochondrial genetic diversity in animals. Science 312: $570-572$.

Bernt M, Braband A, Schierwater B, Stadler PF. 2013a. Genetic aspects of mitochondrial genome evolution. Molecular Phylogenetics and Evolution 69: 328-338.

Bernt M, Donath A, Jühling F, Externbrink F, Florentz C, Fritzsch G, Pütz J, Middendorf M, Stadler PF. 2013 b. MITOS: improved de novo metazoan mitochondrial genome annotation. Molecular Phylogenetics and Evolution 69: 313-319.

Birky CW Jr, Maruyama T, Fuerst P. 1983. An approach to population and evolutionary genetic theory for genes in mitochondria and chloroplasts, and some results. Genetics 103: 513-527.

Bolotov IN, Kondakov AV, Vikhrev IV, Aksenova OV, Bespalaya YV, Gofarov MY, Kolosova ES, Spitsyn VM, Tanmuangpak K, Tumpeesuwan S. 2017a. Ancient river inference explains exceptional oriental freshwater mussel radiations. Scientific Reports 7: 2135.

Bolotov IN, Konopleva ES, Vikhrev IV, Gofarov MY, Lopes-Lima M, Bogan AE, Lunn Z, Chan N, Win T, Aksenova OV, Tomilova AA, Tanmuangpak $\mathrm{K}$, Tumpeesuwan S, Kondakov AV. 2020. New freshwater mussel taxa discoveries clarify biogeographic division of Southeast Asia. Scientific Reports 10: 6616.
Bolotov IN, Vikhrev IV, Bespalaya YV, Gofarov MY, Kondakov AV, Konopleva ES, Bolotov NN, Lyubas AA. 2016. Multi-locus fossil-calibrated phylogeny, biogeography and a subgeneric revision of the Margaritiferidae (Mollusca: Bivalvia: Unionoida). Molecular Phylogenetics and Evolution 103: 104-121.

Bolotov IN, Vikhrev IV, Kondakov AV, Konopleva ES, Gofarov MY, Aksenova OV, Tumpeesuwan S. 2017b. New taxa of freshwater mussels (Unionidae) from a speciesrich but overlooked evolutionary hotspot in Southeast Asia. Scientific Reports 7: 11573.

Bourque JR, Howard Hutchison J, Holroyd PA, Bloch JI. 2015. A new dermatemydid (Testudines, Kinosternoidea) from the Paleocene-Eocene Thermal Maximum, Willwood Formation, southeastern Bighorn Basin, Wyoming. Journal of Vertebrate Paleontology 35: e905481.

Breton S, Beaupré HD, Stewart DT, Hoeh WR, Blier PU. 2007. The unusual system of doubly uniparental inheritance of mtDNA: isn't one enough? Trends in Genetics 23: 465-474.

Breton S, Beaupre HD, Stewart DT, Piontkivska H, Karmakar M, Bogan AE, Blier PU, Hoeh WR. 2009. Comparative mitochondrial genomics of freshwater mussels (Bivalvia: Unionoida) with doubly uniparental inheritance of mtDNA: gender-specific open reading frames and putative origins of replication. Genetics 183: 1575-1589.

Brown W. 1985. The mitochondrial genome of animals. In: MacIntyre R, ed. Molecular evolutionary genetics. New York: Plenum, 95-130.

Brown WM, George M Jr, Wilson AC. 1979. Rapid evolution of animal mitochondrial DNA. Proceedings of the National Academy of Sciences of the United States of America 76: 1967-1971.

Burger BJ. 2012. Northward range extension of a diminutivesized mammal (Ectocion parvus) and the implication of body size change during the Paleocene-Eocene Thermal Maximum. Palaeogeography, Palaeoclimatology, Palaeoecology 363: 144-150.

Burzýnski A, Soroka M, Mioduchowska M, Kaczmarczyk A, Sell J. 2017. The complete maternal and paternal mitochondrial genomes of Unio crassus: mitochondrial molecular clock and the overconfidence of molecular dating. Molecular Phylogenetics and Evolution 107: 605-608.

Carmichael MJ, Inglis GN, Badger MP, Naafs BDA, Behrooz L, Remmelzwaal S, Monteiro FM, Rohrssen M, Farnsworth A, Buss HL. 2017. Hydrological and associated biogeochemical consequences of rapid global warming during the Paleocene-Eocene thermal maximum. Global and Planetary Change 157: 114-138.

Castellana S, Vicario S, Saccone C. 2011. Evolutionary patterns of the mitochondrial genome in Metazoa: exploring the role of mutation and selection in mitochondrial protein coding genes. Genome Biology and Evolution 3: 1067-1079.

Chapman EG, Piontkivska H, Walker JM, Stewart DT, Curole JP, Hoeh WR. 2008. Extreme primary and secondary protein structure variability in the chimeric male-transmitted cytochrome c oxidase subunit II protein in freshwater mussels: evidence for an elevated amino acid 
substitution rate in the face of domain-specific purifying selection. BMC Evolutionary Biology 8: 165.

Chen W, Shen Y, Gan X, Wang X, He S. 2016. Genetic diversity and evolutionary history of the Schizothorax species complex in the Lancang River (upper Mekong). Ecology and Evolution 6: 6023-6036.

Conant GC, Wolfe KH. 2008. GenomeVx: simple webbased creation of editable circular chromosome maps. Bioinformatics 24: 861-862.

Dalziel AC, Moyes CD, Fredriksson E, Lougheed SC. 2006. Molecular evolution of cytochrome c oxidase in high-performance fish (Teleostei: Scombroidei). Journal of Molecular Evolution 62: 319-331.

DeSalle R, Freedman T, Prager EM, Wilson AC. 1987. Tempo and mode of sequence evolution in mitochondrial DNA of Hawaiian Drosophila. Journal of Molecular Evolution 26: 157-164.

Donoghue PC, Yang Z. 2016. The evolution of methods for establishing evolutionary timescales. Philosophical Transactions of the Royal Society B: Biological Sciences 371: 20160020.

Dudgeon D, Arthington AH, Gessner MO, Kawabata Z, Knowler D, Lévêque C, Naiman RJ, Prieur-Richard AH, Soto D, Stiassny MLJ, Sullivan CA. 2006. Freshwater biodiversity: importance, status, and conservation challenges. Biological Reviews 81: 163-182.

Feng X, Tang B, Kodrul TM, Jin J. 2013. Winged fruits and associated leaves of Shorea (Dipterocarpaceae) from the Late Eocene of South China and their phytogeographic and paleoclimatic implications. American Journal of Botany 100: 574-581.

da Fonseca RR, Johnson WE, O’Brien SJ, Ramos MJ, Antunes A. 2008. The adaptive evolution of the mammalian mitochondrial genome. BMC Genomics 9: 119.

Froufe E, Bolotov I, Aldridge DC, Bogan AE, Breton S, Gan HM, Kovitvadhi U, Kovitvadhi S, Riccardi N, Secci-Petretto G, Sousa R, Teixeira A, Varandas S, Zanatta D, Zieritz A, Fonseca MM, Lopes-Lima M. 2020. Mesozoic mitogenome rearrangements and freshwater mussel (Bivalvia: Unionoidea) macroevolution. Heredity 124: 182-196.

Froufe E, Gonçalves DV, Teixeira A, Sousa R, Varandas S, Ghamizi M, Zieritz A, Lopes-Lima M. 2016. Who lives where? Molecular and morphometric analyses clarify which Unio species (Unionida, Mollusca) inhabit the southwestern Palearctic region. Organisms Diversity and Evolution 16: 597-611.

Gallardo B, Bogan AE, Harun S, Jainih L, LopesLima M, Pizarro M, Rahim KA, Sousa R, Virdis SGP, Zieritz A. 2018. Current and future effects of global change on a hotspot's freshwater diversity. The Science of the Total Environment 635: 750-760.

Gingerich PD. 2006. Environment and evolution through the Paleocene-Eocene thermal maximum. Trends in Ecology \& Evolution 21: 246-253.

Graf DL, Cummings KS. 2019. The freshwater mussels (Unionoida) of the world (and other less consequential bivalves). MUSSEL Project Web Site. Stevens Point:
University of Wisconsin. Available at: http://www.musselproject.net/. Accessed 15 May 2019.

Graf DL, Jones H, Geneva AJ, Pfeiffer JM $3^{\text {rd, }}$ Klunzinger MW. 2015. Molecular phylogenetic analysis supports a Gondwanan origin of the Hyriidae (Mollusca: Bivalvia: Unionida) and the paraphyly of Australasian taxa. Molecular Phylogenetics and Evolution 85: 1-9.

Gusman A, Lecomte S, Stewart DT, Passamonti M, Breton S. 2016. Pursuing the quest for better understanding the taxonomic distribution of the system of doubly uniparental inheritance of mtDNA. PeerJ 4: e2760.

Hahn C, Bachmann L, Chevreux B. 2013. Reconstructing mitochondrial genomes directly from genomic nextgeneration sequencing reads-a baiting and iterative mapping approach. Nucleic Acids Research 41: e129.

Hoeh WR, Stewart DT, Guttman SI. 2002. High fidelity of mitochondrial genome transmission under the doubly uniparental mode of inheritance in freshwater mussels (Bivalvia: Unionoidea). Evolution 56: 2252-2261.

Huang X-C, Su J-H, Ouyang J-X, Ouyang S, Zhou C-H, Wu X-P. 2019. Towards a global phylogeny of freshwater mussels (Bivalvia: Unionida): species delimitation of Chinese taxa, mitochondrial phylogenomics, and diversification patterns. Molecular Phylogenetics and Evolution 130: 45-59.

Jacobsen MW, da Fonseca RR, Bernatchez L, Hansen MM. 2016. Comparative analysis of complete mitochondrial genomes suggests that relaxed purifying selection is driving high nonsynonymous evolutionary rate of the NADH2 gene in whitefish (Coregonus ssp.). Molecular Phylogenetics and Evolution 95: 161-170.

Katoh K, Standley DM. 2013. MAFFT multiple sequence alignment software version 7: improvements in performance and usability. Molecular Biology and Evolution 30: 772-780.

Ketmaier V, Giusti F, Caccone A. 2006. Molecular phylogeny and historical biogeography of the land snail genus Solatopupa (Pulmonata) in the peri-Tyrrhenian area. Molecular Phylogenetics and Evolution 39: 439-451.

Kishino H, Hasegawa M. 1989. Evaluation of the maximum likelihood estimate of the evolutionary tree topologies from DNA sequence data, and the branching order in Hominoidea. Journal of Molecular Evolution 29: 170-179.

Konopleva ES, Pfeiffer JM, Vikhrev IV, Kondakov AV, Gofarov MY, Aksenova OV, Lunn Z, Chan N, Bolotov IN. 2019. A new genus and two new species of freshwater mussels (Unionidae) from western Indochina. Scientific Reports 9: 4106.

Kumar S, Stecher G, Li M, Knyaz C, Tamura K. 2018. MEGA X: molecular evolutionary genetics analysis across computing platforms. Molecular Biology and Evolution 35: 1547-1549.

Lanfear R, Frandsen PB, Wright AM, Senfeld T, Calcott B. 2017. PartitionFinder 2: new methods for selecting partitioned models of evolution for molecular and morphological phylogenetic analyses. Molecular Biology and Evolution 34: 772-773.

Laslett D, Canbäck B. 2008. ARWEN: a program to detect tRNA genes in metazoan mitochondrial nucleotide sequences. Bioinformatics 24: 172-175. 
Liu HP, Mitton JB, Wu SK. 1996. Paternal mitochondrial DNA differentiation far exceeds maternal mitochondrial DNA and allozyme differentiation in the freshwater mussel, Anodonta grandis grandis. Evolution 50: 952-957.

Lopes-Lima M, Burlakova LE, Karatayev AY, Mehler K, Seddon M, Sousa R. 2018. Conservation of freshwater bivalves at the global scale: diversity, threats and research needs. Hydrobiologia 810: 1-14.

Lopes-Lima M, Fonseca MM, Aldridge DC, Bogan AE, Gan HM, Ghamizi M, Sousa R, Teixeira A, Varandas S, Zanatta D, Zieritz A, Froufe E. 2017a. The first Margaritiferidae male (M-Type) mitogenome: mitochondrial gene order as a potential character for determining higherorder phylogeny within Unionida (Bivalvia). Journal of Molluscan Studies 83: 249-252.

Lopes-Lima M, Froufe E, Do VT, Ghamizi M, Mock KE, Kebapçı Ü, Klishko O, Kovitvadhi S, Kovitvadhi U, Paulo OS, Pfeiffer JM $3^{\text {rd }}$, Raley M, Riccardi N, Şereflişan H, Sousa R, Teixeira A, Varandas S, Wu X, Zanatta DT, Zieritz A, Bogan AE. 2017b. Phylogeny of the most species-rich freshwater bivalve family (Bivalvia: Unionida: Unionidae): defining modern subfamilies and tribes. Molecular Phylogenetics and Evolution 106: 174-191.

Lopes-Lima M, Hattori A, Kondo T, Hee Lee J, Ki Kim S, Shirai A, Hayashi H, Usui T, Sakuma K, Toriya T, Sunamura $Y$, Ishikawa H, Hoshino $\mathbf{N}$, Kusano $Y$, Kumaki H, Utsugi Y, Yabe S, Yoshinari $Y$, Hiruma $H$, Tanaka A, Sao K, Ueda T, Sano I, Miyazaki JI, Gonçalves DV, Klishko OK, Konopleva ES, Vikhrev IV, Kondakov AV, Yu Gofarov M, Bolotov IN, Sayenko EM, Soroka M, Zieritz A, Bogan AE, Froufe E. 2020. Freshwater mussels (Bivalvia: Unionidae) from the rising sun (Far East Asia): phylogeny, systematics, and distribution. Molecular Phylogenetics and Evolution 146: 106755.

Lydeard C, Mulvey M, Davis GM. 1996. Molecular systematics and evolution of reproductive traits of North American freshwater unionacean mussels (Mollusca: Bivalvia) as inferred from 16S rRNA gene sequences. Philosophical Transactions of the Royal Society of London. Series B, Biological Sciences 351: 1593-1603.

Marko PB. 2002. Fossil calibration of molecular clocks and the divergence times of geminate species pairs separated by the isthmus of Panama. Molecular Biology and Evolution 19: 2005-2021.

Miller MA, Pfeiffer W, Schwartz T. 2010. Creating the CIPRES Science Gateway for inference of large phylogenetic trees. 2010 Gateway Computing Environments Workshop (GCE). New Orleans, LA, USA: IEEE, 1-8.

Minh BQ, Schmidt HA, Chernomor O, Schrempf D, Woodhams MD, von Haeseler A, Lanfear R. 2020. IQ-TREE 2: new models and efficient methods for phylogenetic inference in the genomic era. Molecular Biology and Evolution 37: 1530-1534.

Mittermeier RA, Turner WR, Larsen FW, Brooks TM, Gascon C. 2011. Global biodiversity conservation: the critical role of hotspots. In: Zachos FE, Habel JC, eds. Biodiversity hotspots. Berlin, Heidelberg: Springer, 3-22.
Naafs B, Rohrssen M, Inglis G, Lähteenoja O, Feakins S, Collinson M, Kennedy E, Singh P, Singh M, Lunt D. 2018. High temperatures in the terrestrial mid-latitudes during the early Palaeogene. Nature Geoscience 11: 766.

Oliveira DC, Raychoudhury R, Lavrov DV, Werren JH. 2008. Rapidly evolving mitochondrial genome and directional selection in mitochondrial genes in the parasitic wasp Nasonia (Hymenoptera: Pteromalidae). Molecular Biology and Evolution 25: 2167-2180.

Pennington PT, Cronk QCB, Richardson JA, Lavin M, Schrire BP,Lewis G, Pennington RT, Delgado-Salinas A, Thulin M, Hughes CE, Matos AB, Wojciechowski MF. 2004. Metacommunity process rather than continental tectonic history better explains geographically structured phylogenies in legumes. Philosophical Transactions of the Royal Society of London, Series B: Biological Sciences 359: 1509-1522.

Perna NT, Kocher TD. 1995. Patterns of nucleotide composition at fourfold degenerate sites of animal mitochondrial genomes. Journal of Molecular Evolution 41: 353-358.

Pfeiffer JM, Breinholt JW, Page LM. 2019. Unioverse: a phylogenomic resource for reconstructing the evolution of freshwater mussels (Bivalvia, Unionoida). Molecular Phylogenetics and Evolution 137: 114-126.

Pfeiffer JM, Graf DL. 2015. Evolution of bilaterally asymmetrical larvae in freshwater mussels (Bivalvia: Unionoida: Unionidae). Zoological Journal of the Linnean Society 175: 307-318.

Rambaut A, Drummond AJ, Xie D, Baele G, Suchard MA. 2018. Posterior summarization in Bayesian phylogenetics using Tracer 1.7. Systematic Biology 67: 901-904.

Reid AJ, Carlson AK, Creed IF, Eliason EJ, Gell PA, Johnson PTJ, Kidd KA, MacCormack TJ, Olden JD, Ormerod SJ, Smol JP, Taylor WW, Tockner K, Vermaire JC, Dudgeon D, Cooke SJ. 2019. Emerging threats and persistent conservation challenges for freshwater biodiversity. Biological Reviews of the Cambridge Philosophical Society 94: 849-873.

Ronquist F, Teslenko M, van der Mark P, Ayres DL, Darling A, Höhna S, Larget B, Liu L, Suchard MA, Huelsenbeck JP. 2012. MrBayes 3.2: efficient Bayesian phylogenetic inference and model choice across a large model space. Systematic Biology 61: 539-542.

Roxo FF, Albert JS, Silva GS, Zawadzki CH, Foresti F, Oliveira C. 2014. Molecular phylogeny and biogeographic history of the armored neotropical catfish subfamilies Hypoptopomatinae, Neoplecostominae and Otothyrinae (Siluriformes: Loricariidae). PLoS One 9: e105564.

Rozas J, Ferrer-Mata A, Sánchez-DelBarrio JC, GuiraoRico S, Librado P, Ramos-Onsins SE, SánchezGracia A. 2017. DnaSP 6: DNA sequence polymorphism analysis of large data sets. Molecular Biology and Evolution 34: 3299-3302.

Sambrook J, Fritsch E, Maniatis T. 1989. Molecular cloning: a laboratory manual, 2nd edn. Cold Spring Harbour: Cold Spring Harbour Laboratory Press. 
Sela I, Ashkenazy H, Katoh K, Pupko T. 2015. GUIDANCE2: accurate detection of unreliable alignment regions accounting for the uncertainty of multiple parameters. Nucleic Acids Research 43: W7-14.

Shimodaira H. 2002. An approximately unbiased test of phylogenetic tree selection. Systematic Biology 51: 492-508.

Shimodaira H, Hasegawa M. 1999. Multiple comparisons of log-likelihoods with applications to phylogenetic inference. Molecular Biology and Evolution 16: 1114-1114.

Śmietanka B, Burzyński A, Wenne R. 2010. Comparative genomics of marine mussels (Mytilus spp.) gender associated mtDNA: rapidly evolving atp8. Journal of Molecular Evolution 71: 385-400.

Smith T, Rose KD, Gingerich PD. 2006. Rapid AsiaEurope-North America geographic dispersal of earliest Eocene primate Teilhardina during the Paleocene-Eocene thermal maximum. Proceedings of the National Academy of Sciences of the USA 103: 11223-11227.

Stamatakis A. 2014. RAxML version 8: a tool for phylogenetic analysis and post-analysis of large phylogenies. Bioinformatics 30: 1312-1313.

Stepien CA, Hubers AN, Skidmore JL. 1999. Diagnostic genetic markers and evolutionary relationships among invasive dreissenoid and corbiculoid bivalves in North America: phylogenetic signal from mitochondrial 16S rDNA. Molecular Phylogenetics and Evolution 13: 31-49.

Suchard MA, Lemey P, Baele G, Ayres DL, Drummond AJ, Rambaut A. 2018. Bayesian phylogenetic and phylodynamic data integration using BEAST 1.10. Virus Evolution 4: vey016.

Sun S, Li Q, Kong L, Yu H. 2017. Limited locomotive ability relaxed selective constraints on molluscs mitochondrial genomes. Scientific Reports 7: 10628.

Wächtler K, Mansur MCD, Richter T. 2001. Larval types and early postlarval biology in naiads (Unionoida). In: Bauer G, Wächtler K, eds. Ecology and evolution of the freshwater mussels Unionoida. Berlin: Springer-Verlag, 93-125.
Wilke T, Schultheiß R, Albrecht C. 2009. As time goes by: a simple fool's guide to molecular clock approaches in invertebrates. American Malacological Bulletin 27: $25-45$.

Wing SL, Currano ED. 2013. Plant response to a global greenhouse event 56 million years ago. American Journal of Botany 100: 1234-1254.

Wing SL, Harrington GJ, Smith FA, Bloch JI, Boyer DM, Freeman KH. 2005. Transient floral change and rapid global warming at the Paleocene-Eocene boundary. Science 310: 993-996.

Zieritz A, Bogan AE, Froufe E, Klishko O, Kondo T, Kovitvadhi U, Kovitvadhi S, Lee JH, Lopes-Lima M, Pfeiffer JM, Sousa R, van Do T, Vikhrev I, Zanatta DT. 2018a. Diversity, biogeography and conservation of freshwater mussels (Bivalvia: Unionida) in East and Southeast Asia. Hydrobiologia 810: 29-44.

Zieritz A, Bogan AE, Rahim KAA, Sousa R, Jainih L, Harun S, Razak NFA, Gallardo B, McGowan S, Hassan R, Lopes-Lima M. 2018b. Changes and drivers of freshwater mussel diversity and distribution in northern Borneo. Biological Conservation 219: 126-137.

Zieritz A, Lopes-Lima M, Bogan AE, Sousa R, Walton S, Rahim KA, Wilson JJ, Ng PY, Froufe E, McGowan S. 2016. Factors driving changes in freshwater mussel (Bivalvia, Unionida) diversity and distribution in Peninsular Malaysia. The Science of the Total Environment 571: 1069-1078.

Zieritz A, Taha H, Lopes-Lima M, Pfeiffer J, Wah GSK, Sulaiman Z, McGowan S, Rahim KA. 2020. Towards the conservation of Borneo's freshwater mussels: rediscovery of the endemic Ctenodesma borneensis and first record of the non-native Sinanodonta lauta. Biodiversity and Conservation 29: 2235-2253.

Zouros E. 2013. Biparental inheritance through uniparental transmission: the doubly uniparental inheritance (DUI) of mitochondrial DNA. Evolutionary Biology 40: 1-31.

\section{SUPPORTING INFORMATION}

Additional Supporting Information may be found in the online version of this article at the publisher's web-site:

Figure S1. Original BEAST v.1.10.1 trees obtained for the (A) complete F-type and (B) M-type mitogenome data set, respectively.

Figure S2. Relationship of divergence rates and node age for each female- (F) and male-type (M) mtDNA gene, fragment and the whole mitogenome, calculated based on a fossil-calibrated mitogenomic phylogeny of the Unionidae. For each regression line, $R^{2}$, slope (m) and intercept (b) values are given.

Table S1. Best-fit models of nucleotide substitution for each partition subset based on Bayesian Information Criteria (BIC) using PartitionFinder2 v.2.1.1 (Lanfear et al., 2017) for the Bayesian inference (BI) and maximum likelihood (ML) analyses.

Table S2. List of fossil calibrations that were used in the BEAST analyses. 